\title{
Algorithm for the Identification and Tracking of Convective Cells Based on Constant and Adaptive Threshold Methods Using a New Cell-Merging and -Splitting Scheme
}

\author{
Shingo SHIMIZU \\ National Research Institute for Earth Science and Disaster Prevention, Tsukuba, Japan \\ and \\ Hiroshi UYEDA \\ Hydrospheric Atmospheric Research Center, Nagoya University \\ (Manuscript received 20 April 2010, in final form 17 August 2012)
}

\begin{abstract}
A new method for identifying and tracking convective cells is proposed for the statistical analysis of convective cells embedded within mesoscale convective systems using a two dimensional radar reflectivity dataset. The algorithm for the identification and tracking of convective cells determines convective regions with radar reflectivity exceeding a given constant threshold. The threshold value is gradually increased to detect a cell region with a single peak of reflectivity. The algorithm includes a new cell-merging and -splitting scheme that assumes the conservation of total area of convective cells and the maintenance of their relative locations when merging or splitting occurs, and is termed AITCC (Algorithm for the Identification and Tracking Convective Cells).

The AITCC performance was evaluated in an analysis of 2004 non-severe convective cells (30-40 dBZ) and in 1268 linkages of convective cells (i.e., two successive observations of the same convective cell) observed within meso- $\beta$ convective systems in the Meiyu frontal region. We demonstrated that the AITCC decreased the number of incorrect cell assignments, especially in situations where convective cells are located close together. AITCC showed promising performance (false-alarm-rate $<10 \%)$ in the tracking of weak convective cells $(30-40 \mathrm{dBZ})$ that seemed to be difficult for the previous tracking algorithms. AITCC is expected to enable us to calculate the statistical features of convective cells from their development to dissipation.
\end{abstract}

\section{Introduction}

Convective cells (CCs: list of abbreviations in this paper are shown in Table 1 ) are recognized as a fundamental component of mesoscale convective systems (MCSs). Indeed, many studies based on radar observa-

Corresponding author: Shingo Shimizu, National Research Institute for Earth Science and Disaster Prevention, Tennoudai 3-1, Tsukuba, Ibaraki 305-0006, Japan.

E-mail: shimizus@bosai.go.jp

(C)2012, Meteorological Society of Japan tions have reported that multiple CCs occur as convective region within MCS (Houze et al. 1990; Parker and Johnson 2000). To understand the dynamics or microphysics of the MCS, it is necessary to accurately trace individual cells from their development to dissipation. However, it is difficult to trace the evolution of a cell because 1) CCs may undergo complex processes over the course of their life cycles, including merging and splitting; and 2) the number of CCs during severe weather tends to be too large to enable tracking by manual methods. 
Table 1. List of abbreviations.

\begin{tabular}{ll}
\hline \multicolumn{1}{c}{ Abbreviation } & \multicolumn{1}{c}{ full name } \\
\hline CC & Convective Cell \\
CG & convective Cell Group \\
CCR & Cross-CoRrelatioin \\
OVR & optimal OVeRlapping-area \\
MV & Movement Vector of CG or CC \\
Alone-Child CC (CG) & CC (CG) that was not assignmented by any Parent-CC (CG) \\
AOR & Accumulated Occupation Ratio \\
PF & Penalty Function \\
PV & Principal Vector \\
RC & Removal of Crossing assignment \\
APN & Additional assignment between two Parallel Neighboring assignments \\
\hline
\end{tabular}

Based on radar reflectivity, automated algorithms have been developed in some nowcasting systems for the purpose of cell identification and tracking (TITAN: Dixon and Wiener 1993; SCIT: Johnson et al. 1998; TRACE3D: Handwerker 2002; TRT: Hering et al. 2004; CELLTRACK: Kyznarova and Novak 2009). Most such identification algorithms define a $\mathrm{CC}$ as a contiguous region around the local maximum in the reflectivity field for a given height. Two types of schemes are employed for CC identification: constant threshold schemes (TITAN, SCIT and CELLTRACK), and adaptive threshold schemes (TRACE3D and TRT). Constant threshold schemes enclose a reflectivity region that exceeds a certain threshold value. This threshold value depends on the type of storm: 40-50 $\mathrm{dBZ}$ for individ ual CCs, 30-40 dBZ for a group of CCs, and 25-30 dBZ for an MCS (see Dixon and Wiener 1993). However, when using the constant threshold, it cannot be guaranteed that a single local maximum in reflectivity will exist in the detected target. In contrary, the adaptive threshold method enables the selection of the lowest reflectivity threshold that includes the single local maximum that distinguishes a given CC from nearby CCs (Handwerker 2002). The adaptive threshold method enables the detection of different CCs at individual threshold values depending on the stage of their life cycle (Hering et al. 2004). However, a weakness of this method is that it is unsuitable for statistical analysis because the cell definition varies among different cells.

The greatest difficulty encountered in previous tracking algorithms is the handling of cell merging and splitting, which commonly occurs when many CCs are located close together (e.g., in a squall line). It is generally difficult to distinguish the splitting of a cell into smaller cells from the generation of a new cell near a pre-existing cell. The accurate treatment of merging and splitting is important in tracking the evolution of cells and determining the duration of cell lifetime. However, none of the existing tracking algorithms is able to handle merging and splitting in the case of many cells within a small area.

The aim of the present study is to develop an automated cell identification and tracking method that is able to trace a cell from the developing to dissipating stages using a sophisticated merging and splitting scheme. The scheme assumes the conservation of total area and the maintenance of their relative locations between two successive time points. To this end, we developed the Algorithm for Identification and Tracking of Convective Cell using constant and adaptive threshold (AITCC) which enables us to conduct the statistic analysis of CCs that merge or split and that are embedded in an MCS.

The performance of AITCC is evaluated using observational data obtained during the Meiyu frontal season when non-severe convective cells (30-40 dBZ) are frequently embedded in meso- $\beta$ convective systems (Zhang et al. 2006). In this study, in order to detect a meso $\beta$ convective system in a Meiyu frontal region, the value of $30 \mathrm{dBZ}$ is set as a constant threshold and convective cells are detected at a slightly higher threshold value ( i.e., an adaptiv threshold). A lower threshold value of reflectivity would have negativ effect on the quality of the tracking routines because more object would be detected. Therefore, the tracking of weak convective cells within a meso- $\beta$ convective system is a challenging but necessary task in order to reveal the total life cycle of convective cells in the Meiyu frontal region. 


\section{Methodology and Data}

\subsection{Input data for AITCC}

Most algorithms (e.g., TITAN, SCIT, TRACE3D, TRT, and CELLTRACK) use three-dimensional reflectivity information for the detection of both shallow and deep convective cells. For the tracking procedure, a three-dimensional cell centroid is calculated (e.g., TI TAN, SCIT, or TRACE3D), and the centroids of the former scan are assigned to those of the more recent scan. Otherwise, three-dimensional reflectivity is projected onto a horizontal plane (e.g., the vertical maximum projection of reflectivity: TRT or CELLTRACK) and the tracking is performed using two dimensional objects. However, reflectivity data near the ground surface are often contaminated by ground clutter, and reflectivity data around the melting layer are affected by a bright band that is caused by an intense reflection from melting ice-phase precipitation in the stratiform region; these reflectivity data may be incorrectly interpreted as a convective cell. Therefore, these previous algorithms seek to reduce the occurrence of data contamination and false interpretation. TITAN uses a clutter map that is computed from a number of Cartesian volumes sampled during a period with no significant weather, and TRACE3D ignores reflectivity data from below $1 \mathrm{~km}$ in height as well as cells with a very small vertical extent. CELLTRACK uses a relatively high reflectivity threshold ( $44 \mathrm{dBZ})$ to distinguish convective cells from ground clutter.

AITCC also requires three-dimensional radar reflectivity data as input (i.e., a constant altitude plane positioning indicator (CAPPI) dataset). However, the cell identification and tracking procedures are implemented based on a two-dimensional reflectivity field at a height of $3 \mathrm{~km}$ above sea level (ASL). Three-dimensional reflectivity data are only used to calculate the "bright band fraction" proposed by Chen et al. (2003) as explained below. Thus, AITCC is limited when detecting shallow convective cell below $3 \mathrm{~km}$ ASL. However, most of the convective cells observed in the Meiyu frontal region are expected to be found at a height of $3 \mathrm{~km}$ ASL because climatologically, the statistical analysis by Zhang et al. (2006) indicates that this height is their reflectivity peak.

The lower reflectivity threshold (30 dBZ) used in AITCC permits the detection of the early stages of a convective cell more quickly than that possible using previous algorithms (e.g., the maximum reflectivities in the convective cell must exceed $45 \mathrm{dBZ}$ in TRACE3D, and $44 \mathrm{dBZ}$ in CELLTRACK). However, reflectivity within the bright band or around ground clutter often exceeds 30 dBZ (Handwerker 2002; Kyznarova and Novak 2009), which would impede the performance of cell identification and tracking.

To avoid contamination by the bright band, AITCC performs a classification of precipitation type based on three-dimensional reflectivity according to the "bright band fraction method" (Chen et al. 2003), and the stratiform region is excluded from analysis. Near the radar site, the CAPPI dataset includes data-void regions due to the radar scan geometry. In such situations, precipitation type is classified based on two-dimensional reflectivity (at a height of $3 \mathrm{~km}$ ASL) as proposed by Steiner et al. (1995) to eliminate the stratiform region.

During the Meiyu season, the height of the bright band is climatologically located at a height of 4-5 km ASL (Zhang et al. 2006). We chose a height of $3 \mathrm{~km}$ for our analysis layer to avoid contamination by the bright band, and also to reduce the degree of contamination by ground clutter. AITCC assumes that over flat topography, input data are free of ground clutter above $2 \mathrm{~km}$ ASL.

Reflectivity data suffer from attenuation effects, especially in the case of convective precipitation. Kim et al. (2010) developed a sophisticated method of attenuation correction for dual-polarimetric radar; however, the problem of attenuation effects has yet to be resolved for conventional radar using shorter wavelength (e.g., X-band). AITCC does not implement an attenuation correction scheme; however, conventional attenuation correction for convective precipitation (Doviak and Zrnić 1993) should be applied prior to running AITCC.

Rossenfeld (1987) proposed that the horizontal resolution of input data for cell identification should be better than the lower limit of the meso-gamma scale (i.e., $2 \mathrm{~km}$, as derived from the definition provided by Orlanski 1975). In AITCC, a convective cell is defined as the region enclosing a single local peak in reflectivity within a horizontal distribution. To define the local peak in the minimum convective cell (diameter of $2 \mathrm{~km}$ ), the resolution should be $1 \mathrm{~km}$ or better. Therefore, it is desirable for AITCC that (1) the antenna beam width should be less than about $1^{\circ}$, and (2) the maximum range of cell detection should be less than $60 \mathrm{~km}$ considering the range-dependent nature of the resolution.

\subsection{Data for evaluating AITCC performance}

To evaluate the performance of AITCC, we used both radar observational data and simulation data with a resolution of $1 \mathrm{~km}$. Many mesoscale rainbands observed between 0100 local standard time (LST = 
UTC +8 hours) and 0900 LST on 24 June 2001 in the Meiyu frontal zone associated with typhoon Chebi (Geng et al. 2004) were selected for evaluating the performance of AITCC in tracking cells.

To reveal how the tracking performance of AITCC depends on the time resolution of the input dataset, we applied AITCC to simulation data at various temporal resolutions (high resolution: $1 \mathrm{~min}$; standard resolution: 5-6 min; coarse resolution: $10 \mathrm{~min}$ ). In Section 4, we compare the tracking performance using time resolutions of $1 \mathrm{~min}, 5 \mathrm{~min}$, and $10 \mathrm{~min}$.

\section{a. Observational data}

Observation data were obtained by an X-band Doppler radar installed at Zhouzhuang, China in the downstream region of the Yangtze River (Fig. 1), for the period from June to July 2001 (Yamada et al. 2003; Geng et al. 2004). The observation data provide three-dimensional information at fine spatial and temporal resolutions, as required for investigating convective cells. The radar, covering an area with a range of $64 \mathrm{~km}$, recorded sets of volume scans of reflectivity and Doppler velocity every $6 \mathrm{~min}$. The sampling resolution of the radar data was $250 \mathrm{~m}$ in the radial direction and $1.0^{\circ}$ in the azimuthal direction. Each volume scan consisted of 16 elevation angles $\left(0.7^{\circ}, 1.0^{\circ}, 1.3^{\circ}, 1.7^{\circ \circ}, 2.1^{\circ}, 2.7^{\circ}, 3.4^{\circ}, 4.3^{\circ}, 5.4^{\circ}, 6.8^{\circ}\right.$, $8.6^{\circ}, 10.9^{\circ}, 13.7^{\circ}, 17.4^{\circ}, 22.2^{\circ}$, and $28.5^{\circ}$ ). We determined the region of ground clutter on no-precipitation days at lower elevation-angle scans. In compiling the CAPPI dataset, we ignored the azimuth corresponding to the region covered by lower-elevation scans.

The attenuation of reflectivity due to rain was simply corrected by using the relationship between specific attenuation $K\left(\mathrm{~dB} \mathrm{~km}^{-1}\right)$ and rainfall intensity $R(\mathrm{~mm}$ $\mathrm{hr}^{-1}$ ) as described by Doviak and Zrnić (1993), and by using the following $Z-R$ relationship as described by Fujiwara (1965) for rainshowers:

$$
\begin{aligned}
& K=0.01 R^{1.21} \\
& Z=300 R^{1.37}
\end{aligned}
$$

The reflectivity radar data were interpolated in a Cartesian coordinate system with a 1-km horizontal grid interval for obtaining the reflectivity distribution at a height of $3 \mathrm{~km}$ ASL. For the interpolation, a Cressman-type weighting function (Cressman 1959) was used. The effective radius of influence in the weighting function was fixed to $1 \mathrm{~km}$ in the horizontal and in the vertical.

The total number of cells detected by AITCC ever 6 min, which includes multiple counts of a given cell at

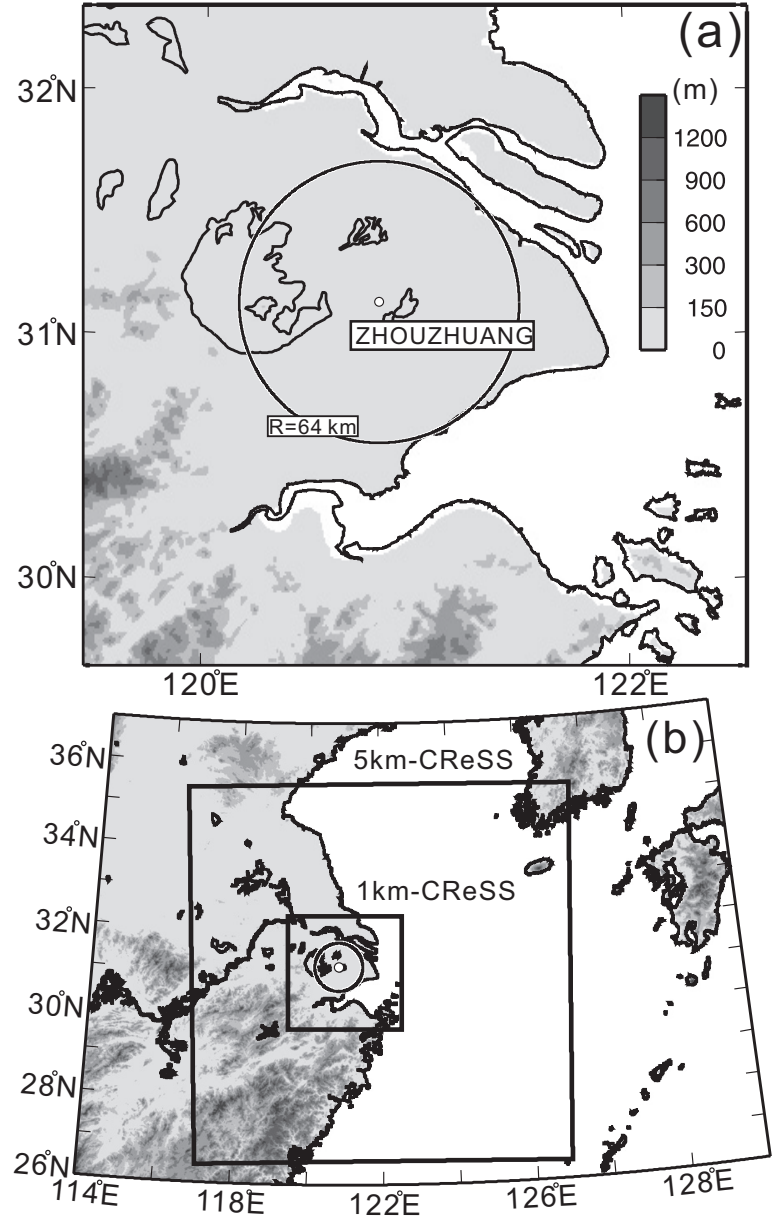

Fig. 1. Observation area and simulation domain of $1 \mathrm{~km}-\mathrm{CReSS}$ and $5 \mathrm{~km}-\mathrm{CReSS}$. X-band Doppler radar was installed at Zhouzhuang, China. Gray shade indicates topography height. The upper figure indicates the entire domain of $1 \mathrm{~km}$ CReSS.

different time points, was 2004. On average, 25.1 cells ( $=2004 / 80$ scans) were detected at each scan between 0100 and 0900 LST. Cell tracking within the observation domain was achieved for 255 cells with a lifetime of at least two volume scans. In terms of cells with a lifetime of 6-min (instantaneous cells), we identified 324 cells in the observation data. Thus, the average lifetime of cells, excluding instantaneous cells, was $39.5 \min (=(2004-324) / 255 \times 6 \mathrm{~min})$.

\section{b. Numerical simulation data}

To obtain the simulated reflectivity dataset for the observed rainband, we performed a simulation using 
the cloud-resolving storm simulator (CReSS) with $1-\mathrm{km}$ resolution $(1 \mathrm{~km}-\mathrm{CReSS})$. CReSS is a three-dimensional non-hydrostatic model developed by the Hydrospheric Atmospheric Research Center (HyARC) of Nagoya University, Japan (Tsuboki and Sakakibara 2002). It uses a quasi-anelastic set of momentum, continuity, and thermodynamic equations, and includes a two-moment bulk cold-rain parameterization (Murakami 1990; Murakami et al. 1994) and a 1.5 -order closure with turbulent kinematic energy pre diction (Tsuboki and Sakakibara 2001). The details of other characteristics of CReSS are described in Tsuboki and Sakakibara (2001).

The initial and lateral boundary conditions in the CReSS model were provided by outputs of the JMA Regional Spectrum Model (Saito et al. 2001). Domains of the version of CReSS with $5-\mathrm{km}$ resolution $(5 \mathrm{~km}-\mathrm{CReSS})$ and $1 \mathrm{~km}-\mathrm{CReSS}$ were nested in the RSM domain as shown in Fig. 1. The 5km-CReSS simulation was integrated forward in time using the RSM output data at 2000 LST on 23 June 2001. The initial and lateral boundary data of $1 \mathrm{~km}-\mathrm{CReSS}$ were obtained from the $5 \mathrm{~km}-\mathrm{CReSS}$ results. The initial time of the $1 \mathrm{~km}$-CReSS simulation was 0300 LST on 24 June 2001 and the forecast period was 6 hours.

To calculate reflectivity from the mixing ratio of rain (Roux 1985), snow (Churchill and Houze 1984), and graupel (Hauser and Amayenc 1986), the following equations are used:

$$
\begin{aligned}
Z= & 2.51 \times 10^{9}\left(\rho q_{r}\right)^{1.63}+2.66 \times 10^{8}\left(\rho q_{s}\right)^{1.65} \\
& +2.15 \times 10^{10}\left(\rho q_{g}\right)^{1.75}
\end{aligned}
$$

Here, $q_{r}\left(\mathrm{~kg} \mathrm{~kg}^{-1}\right), q_{s}\left(\mathrm{~kg} \mathrm{~kg}^{-1}\right)$, and $q_{g}\left(\mathrm{~kg} \mathrm{~kg}^{-1}\right)$ are the mixing ratios of rain, snow, and 4 graupel respectively, $\rho\left(\mathrm{kg} \mathrm{m}^{-3}\right)$ is air density, and $Z\left(\mathrm{~mm}^{6} \mathrm{~m}^{-3}\right)$ is reflectivity factor.

\subsection{Identification algorithm}

First, AITCC detects the cell group (CG) and divides it into several convective cells (CCs). The CG detection part of AITCC consists of the following seven steps (Table 2). In step A1, the stratiform region is excluded using the classification methods proposed by Chen et al. (2003) or Steiner et al. (1995). In step A2, reflectivity data are quantized every $0.5 \mathrm{dBZ}$, thereby simplifying the detection of peaks in reflectivity. The value of $0.5 \mathrm{dBZ}$ is the ordinary limit of precision in reflectivity (Gekat et al. 2003). In step A3, the local peaks of the eight neighboring points are detected. In the case where two peaks are located within $2 \mathrm{~km}$ of each other, the peak with weaker reflectivity is deleted. If the two peaks have the same reflectivity, then the
Table 2. Flow chart showing the process of $\mathrm{CG}$ and $\mathrm{CC}$ identification.

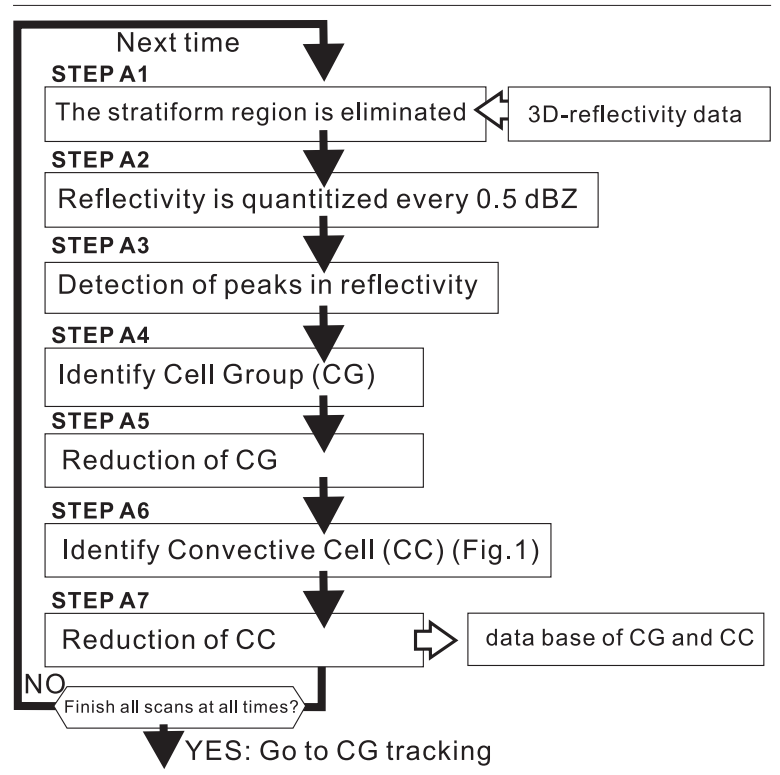

average reflectivity around the peak is compared. If there are more than two peaks located within $2 \mathrm{~km}$, then a special treatment is applied. Let us consider an example where four peaks $(37,40,44$, and $48 \mathrm{dBZ})$ are located in a line from east to west, each separated from the next by $2 \mathrm{~km}$. In the first step, a single peak is deleted in turn, from lowest to highest reflectivity. However, in this case the deletion of a single peak is insufficient. In the second step, two of the four peaks are deleted in the order of increasing sum of two reflectivity (first, 37 and $40 \mathrm{dBZ}$; second, 37 and $44 \mathrm{dBZ}$; third, 40 and $44 \mathrm{dBZ}$; finally, 44 and $48 \mathrm{dBZ}$ ). In this case, the deletion of two peaks (both 37 and $44 \mathrm{dBZ}$ ) satisfies the requirement that the distance between neighboring peaks is greater than $2 \mathrm{~km}$. This treatment is continued until all the remaining peaks are located more than $2 \mathrm{~km}$ from neighboring peaks.

In step $\mathrm{A} 4$, a $\mathrm{CG}$ is defined as a contiguous region of $\geq 30 \mathrm{dBZ}$ (corresponding to $2 \mathrm{~mm} \mathrm{~h}^{-1}$ ) following the conventional definition proposed by Hilgendorf and Johnson (1998) and Dixon and Wiener (1993). The properties of the CG are calculated, including its area, number of peaks, and location of the centroid. If the area of the $C G$ is less than $4 \mathrm{~km}^{2}$, it is not regarded as a meteorological target (step A5).

In step A6, the CG is divided into several CCs. To detect a cell region that includes a single peak of reflectivity, the threshold of reflectivity is gradually increased in steps of $0.5 \mathrm{dBZ}$ until a single peak is included in the 

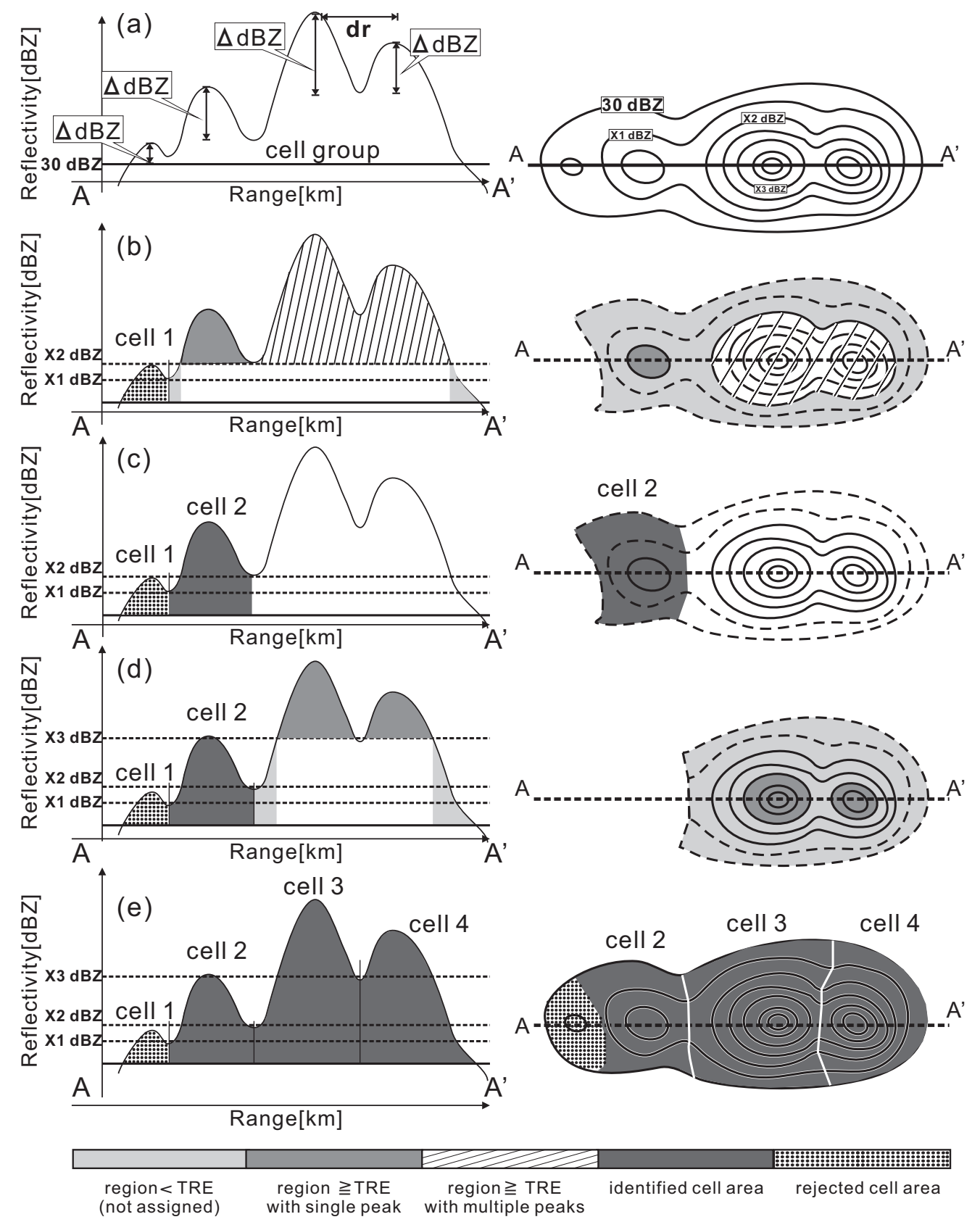

Fig. 2. Schematic sketches of identification methods of convective cells: horizontal reflectivity distribution (right column) and reflectivity along A-A' line (left column). Solid (broken) contours in right column indicates reflectivity larger (smaller) than a given threshold value. ' $\triangle \mathrm{dBZ}$ ' indicates the difference between the peak of reflectivity and the minimum reflectivity which can be used to distinguish a peak in reflectivity from nearby peaks. 'dr' indicates the minimum distance from the nearest neighboring CC peak. Cells which have too small ' $\Delta \mathrm{dBZ}$ ' or too small 'dr' will be deleted. The threshold of reflectivity (TRE) is increased in $0.5 \mathrm{dBZ}$ steps until a single peak is included in the cell region. The light-gray region indicates the region of less than a given threshold. The medium-gray region indicates the region of equal or more than the given threshold with single reflectivity peak. The hatched region is same for medium-gray region but for multiple reflectivity peaks. The dark-gray region indicates the final cell region. The dotted region indicates the rejected cell region. The light-gray region is distributed to the nearest medium-gray region or hatched region. 
cell region (Fig. 2a). When a single peak is found in a cell region that is enclosed by a reflectivity contour with a value exceeding the given threshold (e.g., X1 dBZ or $\mathrm{X} 2 \mathrm{dBZ}$ in Fig. 2b), there are three regions in the cell group: the first is the region with reflectivity that exceeds the threshold with a single peak (medium-gray region in Fig. 2b), the second is the region with reflectivity that exceeds the threshold with multiple peaks (hatched region in Fig. 2b), and the third is the region with reflectivity less than the threshold (light-grayregionin Fig. 2b). Each grid in the third region is distributed to the first or second regions depending on whether the grid is closer to the edge of the first region or the second region. The first region and grids in the third region which are distributed to the first region together are regarded as a cell region (cell 2 in Fig. 2c). If the difference between the peak reflectivity and the threshold (' $\Delta d \mathrm{BZ}$ ' in Fig. $2 \mathrm{a}$ ) is less than $2 \mathrm{dBZ}$, the cell region is deleted (see cell 1, "hatched region" in Fig. 2b). This process is repeated with an increased threshold (e.g., X3 dBZ in Fig. 2d) in order to detect a single peak for the second region and the grids in the third region which are distributed to the second region (Fig. 2d). If all cell regions corresponding to each peak are identified in the cell group, Step A6 is terminated (Fig. 2e).

In this approach, we have combined the constant and adaptive threshold methods. Therefore, cells identified in AITCC can be defined as an enclosed region of $\geq 30$ $\mathrm{dBZ}$ with a single reflectivity core. Similarly, Handwerker (2002) used an adaptive threshold method to identify the cell region (Fig. 2 in Handwerker 2002), although without the distribution process. His approach is unsuitable for statistical analysis because the cell definition varies among different cells.

Finally, in Step A7, we deleted those CCs that do not satisfy the following conditions: 1) the area of the $\mathrm{CC}$ is $\geq 4 \mathrm{~km}^{2}$; and 2) the distance from the nearest neighboring $\mathrm{CC}$ peak is $>2 \mathrm{~km}$ ( $d r$ in Fig. $2 \mathrm{a})$.

\subsection{Tracking algorithm}

The goal of the tracking is to link objects in consecutive radar images at times $\mathrm{T}$ and $\mathrm{T}+\mathrm{dt}$ if they represent the same phenomenon. In this study, the terms parent and child are used to provide a short, intuitive description of the temporal order as proposed by Handwerker (2002). A parent-cell $(t=T)$ and a child-cell $(t=T+d t)$ are two successive observations of the same convective cell.

After detecting all CGs and CCs in all time steps, AITCC assigns the CGs between $\mathrm{t}=\mathrm{T}$ and $\mathrm{T}+\mathrm{dt}$. Next, AITCC tracks the CCs in addition to CGs. This order is followed because it is much easier to track CGs than to track CCs, and because moving vector (MV) of a CG
Table 3. Flow chart showing the process of tracking CGs.

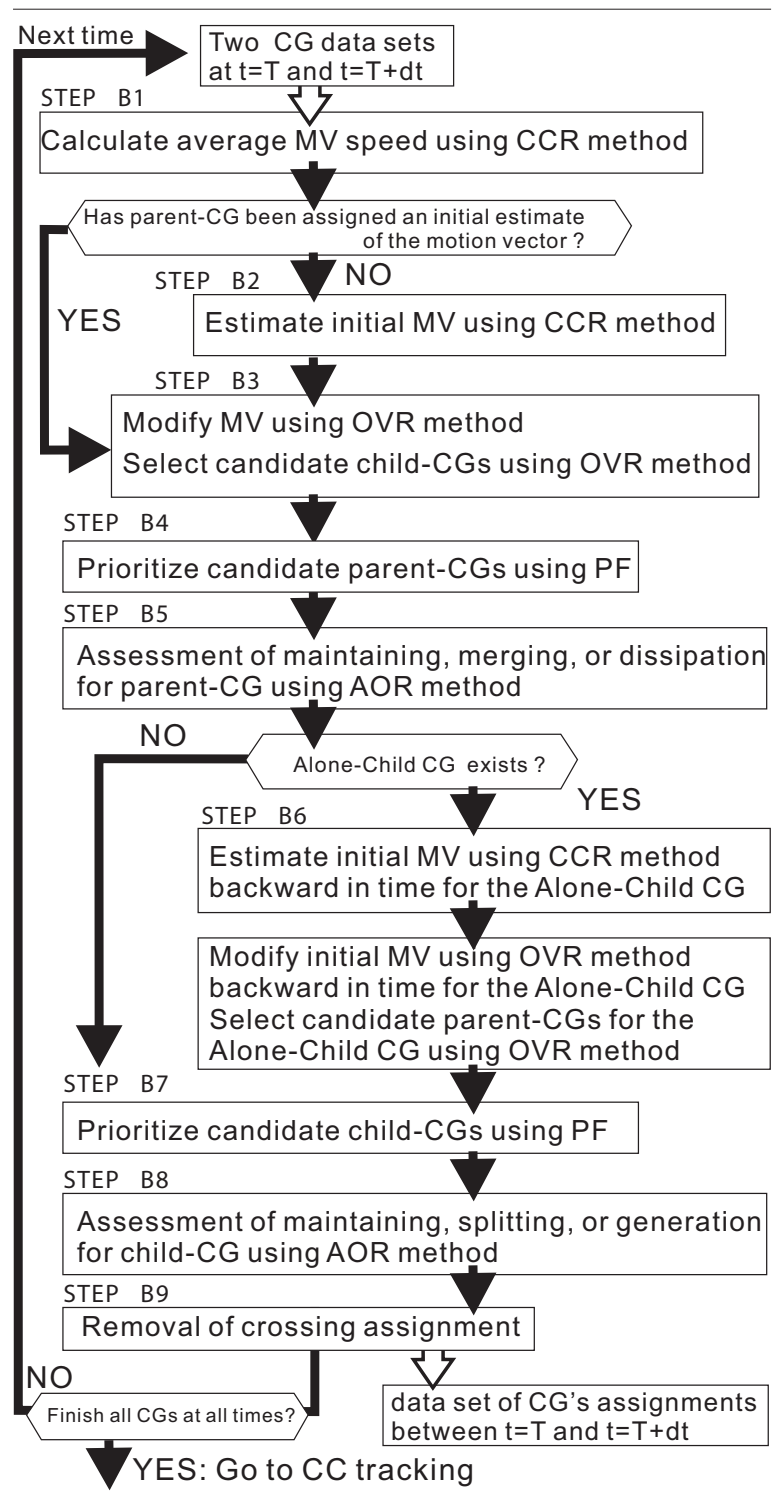

is used as an initial estimate of the MV of a given CC within the CG.

The CG tracking process flowchart is shown in Table 3. In step B1, AITCC uses a Cross-CoRrelation method (CCR: Rinehart and Garvey 1978) to assess the entire region between $\mathrm{t}=\mathrm{T}$ and $\mathrm{t}=\mathrm{T}+\mathrm{dt}$ to obtain the averaged MV of the precipitation system. For a $\mathrm{CG}$ without an initial estimate of MV (e.g., CGs generated at a given time), $C C R$ is applied to provide an initial estimate of the CG's MV (Step B2). In Step B3, MV is modified to find the optimal MV that maximizes the area of CG overlap between $\mathrm{t}=\mathrm{T}$ and $\mathrm{t}=\mathrm{T}+\mathrm{dt}$ (optimal OVeRlapping-area (OVR) method in Fig. 3). A 
(a) Definition of the overlapping between two cells

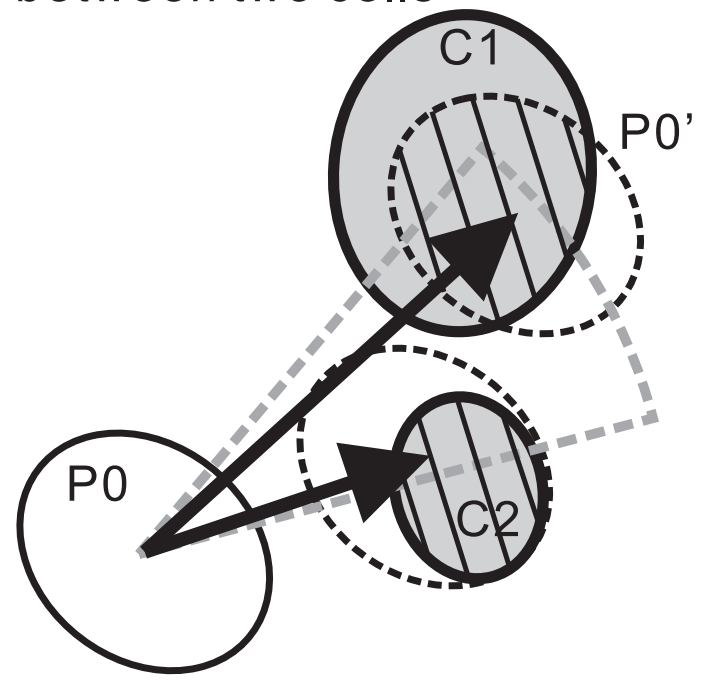

$\mathrm{t}=\mathrm{T} 0$

$\mathrm{t}=\mathrm{T} 0+\mathrm{dT}$

(b) Moving vector modification

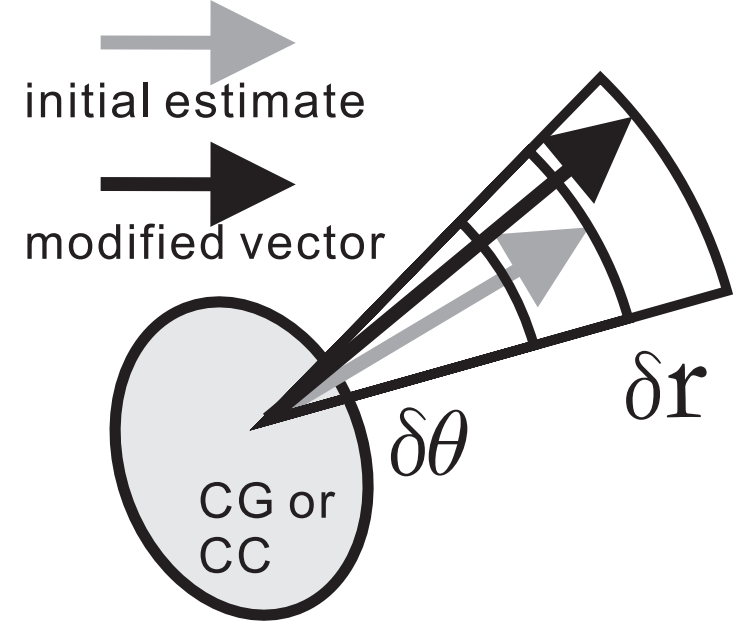

Fig. 3. Schematic sketches of (a) optimal overlapping-area method and (b) modification of initial movement vector by adding perturbations in direction $(\delta \theta)$ and length ( $\delta \mathrm{r})$ to find optimal movement vector that maximizes the area of overlap of CGs (or CCs) between at $\mathrm{t}=\mathrm{T}$ and $\mathrm{t}=$ $\mathrm{T}+\mathrm{dt}$. $\mathrm{P} 0$ indicates $\mathrm{CG}$ (or CC) at $\mathrm{t}=\mathrm{T}$. $\mathrm{P} 0$ ' is the translated $\mathrm{P} 0$ by movement vector. $\mathrm{C} 1$ and $\mathrm{C} 2$ indicate CGs (or CCs) at $\mathrm{t}=\mathrm{T}+\mathrm{dt}$.
parent-CG is translated using MVs modified by adding perturbations in direction and length (Fig. 3). In the case that multiple optimal MVs are found that maximize the area of overlap, the MV located closest to the centroid of the child-CG is selected. If an overlapping area is found for at least one grid point when using MVs, the $\mathrm{CG}$ at $\mathrm{t}=\mathrm{T}+\mathrm{dt}$ becomes a potential child-CG to the parent-CG. A parent-CG can be assigned to two or more child-CGs provided that an overlapping area exists.

In Step B4, to prioritize the candidate parents linked to a given child, we calculate the priority function (PF), which is a non-dimensional function defined in Eq. (4). The larger the PF of the parent, the higher its priority as a candidate to be matched with the child. A large PF indicates that the parent is similar to the child in terms of area, MV, and reflectivity intensity.

$$
\begin{aligned}
& p f 1=\exp \left(-\left(\frac{\delta A}{A}\right)^{2}\right) \\
& p f 2=\exp \left(-\left(\frac{U-U_{c g}}{U_{c g}}\right)^{2}\right) \\
& p f 3=\exp \left(-\left(\frac{V-V_{c g}}{V_{c g}}\right)^{2}\right) \\
& p f 4=\exp \left(-\left(\frac{\delta R E F_{\text {mean }}}{R E F_{\text {mean }}}\right)^{2}\right) \\
& p f 5=\exp \left(-\left(\frac{\delta R E F_{\text {max }}}{R E F_{\text {max }}}\right)^{2}\right) \\
& \text { pf } 6=\exp \left(-(1-C C R)^{2}\right) \quad(C C R \geq 0) \\
& \text { PF }=\sum_{i=1}^{6} w_{i} * p f_{i}
\end{aligned}
$$

where, $w$ is the weighting coefficient for each term; $A$ is the area of the parent; $U$ and $V$ are the x-and y-components of the MV of the parent, respectively; $U_{c g}$ and $V_{c g}$ are the $\mathrm{x}$ and y-components of the MV of the cell group, respectively; $R E F_{\text {mean }}$ and $R E F_{\text {max }}$ are the mean reflectivity (unit is $\mathrm{dBZ}$ ) and the maximum reflectivity (unit is dBZ) of the parent, respectively; $C C R$ is the maximum cross-correlation between the parent and the child; and $\delta$ indicates that the associated value is the difference between the parent and child values. In this study, all weighting coefficients were set to 1.0. In the case that the denominator in a given term is zero, 
the term is set to a value of 0.0 . In the case that $C C R$ is negative, $p f 6$ is set to a value of 0.0 . To calculate the maximum $C C R$, we consider the reflectivity in the rectangular region that includes the parent if the area of the parent is larger than that of the child. If the area of the child exceeds that of parent, then we consider the rectangular region that includes the child. $C C R$ is calculated at overlapping grid points between the parent and child. The rectangle is then displaced by a given number of grid points in all directions, assuming that the movement speed is less than $1 \mathrm{~km}$ per $1 \mathrm{~min}$ (16.7 $\mathrm{ms}^{-1}$ ), to find the maximum $C C R$.

The OVR method usually selects too many linkages between $\mathrm{t}=\mathrm{T}$ and $\mathrm{t}=\mathrm{T}+\mathrm{dt}$; that is, too many merging and splitting assignments are made. To assess the merging assignments in CG tracking (Step B5), the Accumulated Occupation Ratio $(A O R)$ method is applied, and some candidate parent-CGs for a given child-CG are rejected. When a child has multiple candidate parents (Fig. 4a), AITCC calculates the ratio of the area of each parent to that of the child (the occupation ratio). The ratio is calculated for each parent in the order of decreasing priority as assigned in advance (Eq. 5).

$$
A O R=\sum_{i}^{n \leq N} \frac{A_{p i}}{A_{c}}
$$

where $A O R$ is the accumulated occupation ratio; $A_{c}$ and $A_{p}$ are the area of the child and parent, respectively; $i$ indicates the order of priority; and $N$ is the number of candidates. $A O R$ is not always the sum up to $N$, but only the sum up to some $n \leq N$ where $\mathrm{n}$ is the smallest number producing a sum larger than a certain threshold (e.g., typically 1.0-1.3, in this study, 1.0 is used). When $A O R$ exceeds the threshold, the residual parent-candidates $(i>n)$ are rejected ("CCp3" in Fig. 4a). This approach assumes that smaller parents merge into a larger child. The AOR scheme assumes the conservation of the total area when merging or splitting occurs.

After step B5, appropriate child-CGs are selected for parent-CGs (forward-in-time procedure). The forwardin-time procedure categorizes all parent-CGs into one of three stages: maintaining (having one child), dissipated (having no child), or splitting (having multiple children). After the forward-in-time procedure, AITCC looks for unassigned child-CGs (termed Alone-child CGs). In step B6, a candidate parent-CG is sought for each Alone child CG (backward-in-time procedure). First, we estimate the initial MV of Alone-child CGs using the $C C R$ method backward in time, and then modify the MV using the OVR method. If an overlapping area is found for at least one grid point when
JUDGEMENT of MERGING or DISSIPATION

(a) Area-Occupation Ratio method (b) Principal Vector method
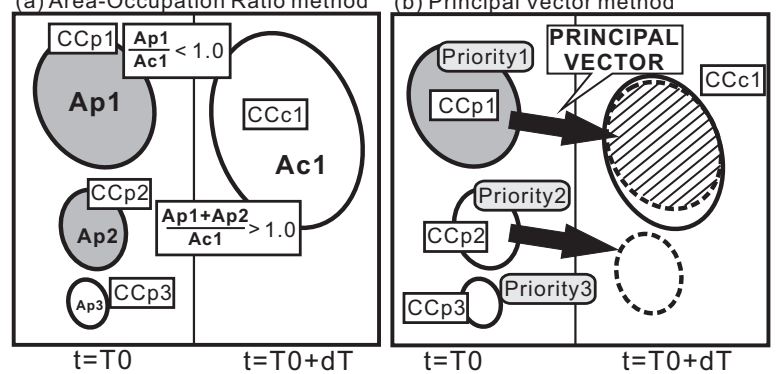

JUDGEMENT of SPLITTING or GENERATION

(c) Area-Occupation Ratio method (d) Principal Vector method

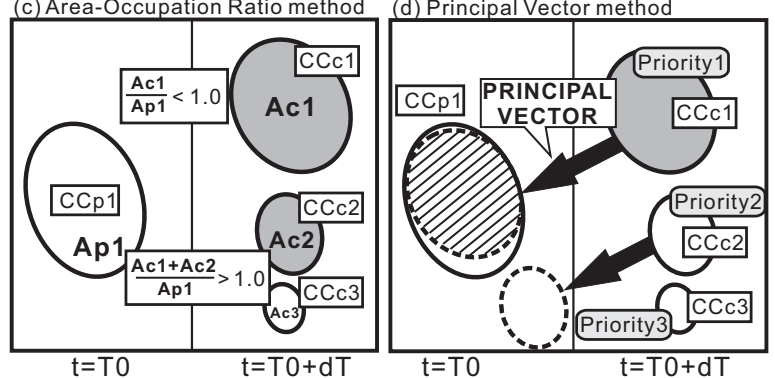

Fig. 4. Schematic sketches of (a) AOR method and (b) PV method for the assessment of maintaining, merging, or dissipation of parent-CCs (or parent-CGs), and (c) AOR method and (d) PV method for the judgment of maintaining, splitting, or generation of child-CCs (or childCGs). Gray-colored CCs (CGs) are accepted by AOR or PV method. Fig. 4a: For a given cell at $t$ $=\mathrm{T}+\mathrm{dt}(\mathrm{CCc} 1)$, three cells $(\mathrm{CCp} 1-3)$ at $\mathrm{t}=\mathrm{T}$ are potential parents. $\mathrm{CCp} 1, \mathrm{CCp} 2$, and $\mathrm{CCp} 3$ have the first, second, and third priority respectively, based on penalty function. Ac1, Ap1, Ap2, and Ap3 indicate the area of CCc1, CCp1, CCp2, and $\mathrm{CCp} 3$, respectively. Using AOR method, CCp1 and CCp2 are accepted because Ap1 is less than Ac1, while CCp3 is rejected because Ap1+Ap2 exceeds Ac1. Fig. 4b: Movement vector from the first-priority parent-CC to the child$\mathrm{CC}$ is estimated using optimal OVR method (named as principal vector: PV). The other candidate parent-CCs are transposed using the PV. If there exists overlap between the candidates and the child-CC, multiple assignments are finally allowed. $\mathrm{CCp} 2$ is rejected because no overlap between $\mathrm{CCc} 1$ and CCp2 using PV. Figs. 4c and $4 \mathrm{~d}$ are same for Figs. $4 \mathrm{a}$ and $4 \mathrm{~b}$ respectively, but for assessment of maintaining, splitting, or generation of child-CCs (child-CGs).

using some MVs (Fig. 3), the $\mathrm{CG}$ at $\mathrm{t}=\mathrm{T}$ becomes a potential parent-CG to the Alone-child CG. If no overlapping area is found, the Alone-child CGs are then 
regarded as generated CGs.

After the backward-in-time procedure, some child-CGs will have been assigned candidate parent-CGs. In Step B7, PF is calculated to prioritize the candidate children linked to a given parent. When a parent has multiple children (Fig. 4c), the AOR method is applied to select an appropriate child-CG for the parent-CG (Step B8). The backward-in time procedure categorizes all child-CGs into one of three stages: maintaining (having one parent), generated (having no parent), or merging (having multiple parents).

Finally, in Step B9, AITCC rejects all assignments that cross each other (Fig. 5a). If two or more assignments cross each other, the average MV estimated in step B1 is used to determine the most suitable vector; the best of the assigned vectors is then accepted following Handwerker (2002). This algorithm helps to reject less-credible linkages.

After applying the CG-tracking procedure, CC tracking is performed in a similar manner to the CG-tracking procedure (Table 4). If a parent-CC does not have an initial estimate of MV (e.g., CCs generated at a given time), the MV of the CG to which the parent $\mathrm{CC}$ belongs is used as the initial estimate of $\mathrm{MV}$ of the parent-CC. The initial estimate of MV is modified, and candidate child-CCs for a given parent-CC are selected using the OVR method (Step C1). Using $\mathrm{PF}$, the priority of parent-CCs is determined for a given child-CC (Step C2).

To assess the merging assignments of parent $\mathrm{CCs}$, the $A O R$ method and another condition are employed, especially for cell tracking (Step C3). For the parent-CC assigned the highest priority for a given child-CC (herein termed the "principal parent"), the MV from the parent to the child is estimated using the OVR method (Fig. 4b). This MV is referred to as the "principal vector" (PV). The candidate parent-CCs, except for the "principal parent", are transposed using the PV. If there exists overlap between the candidates and the child-CC, merging is finally allowed. The PV scheme considers the relative locations of cells when merging or splitting occur.

After step C3, parent-CCs select appropriate child-CCs (forward-in-time procedure) and the forward-in-time procedure categorizes all parent-CCs into one of three stages: maintained (having one child), dissipated (having no child), or splitting (having multiple children). Similarly to step B6, Alone-child $\mathrm{CC}$ finds a potential parent-CC using the CCR and OVR methods backward in time (Step C4).

In Step C5, PF is calculated to prioritize the candidate child-CCs linked to a given parent-CC. Similarly

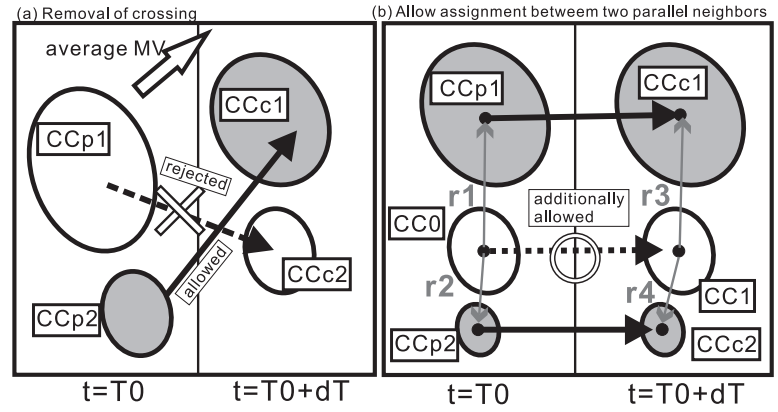

Fig. 5. Schematic sketches of (a) removal of crossing method and (b) additionally accepted assignment between two parallel neighboring assignments. Fig. 5a: By removal of crossing, a linkage between $\mathrm{CCp} 1$ and $\mathrm{CCc} 2$ is rejected because the assignment vector between $\mathrm{CCp} 2$ and $\mathrm{CCcl}$ is good agreement with the average MV. Fig. 5b: $\mathrm{CC} 0$ and $\mathrm{CC} 1$ are no-assignment cells, respectively. The assignment between $\mathrm{CC} 0$ and $\mathrm{CC} 1$ is accepted if several conditions are satisfied (see text). r1 and $\mathbf{r} \mathbf{2}(\mathbf{r} \mathbf{3}$ and $\mathbf{r} 4)$ indicate the vectors from the peak of $\mathrm{CC} 0(\mathrm{CC} 1)$ to that of $\mathrm{CCp} 1$ and $\mathrm{CCp} 2$ (CCc1 and $\mathrm{CCc} 2$ ), respectively.

to step $\mathrm{C} 3$, the AOR and PV methods determine the appropriate child-CC for the parent-CC. Finally, in step C6, all child-CCs are categorized into one of three stages: maintaining (having one parent), generated (having no parent), or merging (having multiple parents). In Step C7, the RC method is applied to reject all assignments that cross each other.

In Step C8, AITCC allows an Additional assignment between two Parallel Neighboring assignments (the APN method in Fig. 5b) provided that the following conditions are satisfied:

1. The No-child cell at $\mathrm{t}=\mathrm{T}(\mathrm{CC} 0$ in Fig. $5 \mathrm{~b})$ and the No-parent cell at $\mathrm{t}=\mathrm{T}+\mathrm{dt}(\mathrm{CC} 1$ in Fig. $5 \mathrm{~b})$ are within $10 \mathrm{~km}$ of each other.

2. The two parent-CCs nearest to the $\mathrm{CCO}$ are selected at $\mathrm{t}=\mathrm{T}(\mathrm{CCp} 1$ and $\mathrm{CCp} 2$ in Fig. 5b) and their children are determined ( $\mathrm{CCc} 1$ and $\mathrm{CCc} 2$ in Fig. $5 b$ ). The vector from the peak location of $\mathrm{CC} 0$ to that of $\mathrm{CCp} 1$ (r1 in Fig. 5b) is calculated. Similarly, we calculate $\mathbf{r 2}$ (vector from $\mathrm{CC} 0$ to $\mathrm{CCp} 1$ ), $\mathbf{r} 3$ (vector from $\mathrm{CC} 1$ to $\mathrm{CCc} 1$ ), and $\mathbf{r} 4$ (vector from $\mathrm{CC} 1$ to $\mathrm{CCc} 2$ ). The norms of $\mathbf{r} 1, \mathbf{r} \mathbf{r} \mathbf{3}$, and $\mathbf{r} \mathbf{4}$ are less than $10 \mathrm{~km}$.

3. The inner product of $\mathbf{r} \mathbf{1}$ and $\mathbf{r} \mathbf{2}$ divided by the product of their magnitudes is less than -0.7 . This means that the crossing angle of the two vectors is ranges from 135 to $225^{\circ}$.

4. The vectors $\mathbf{r} \mathbf{3}$ and $\mathbf{r} \mathbf{4}$ similarly satisfy the above 
Table 4. Flow chart showing the process of tracking CCs.

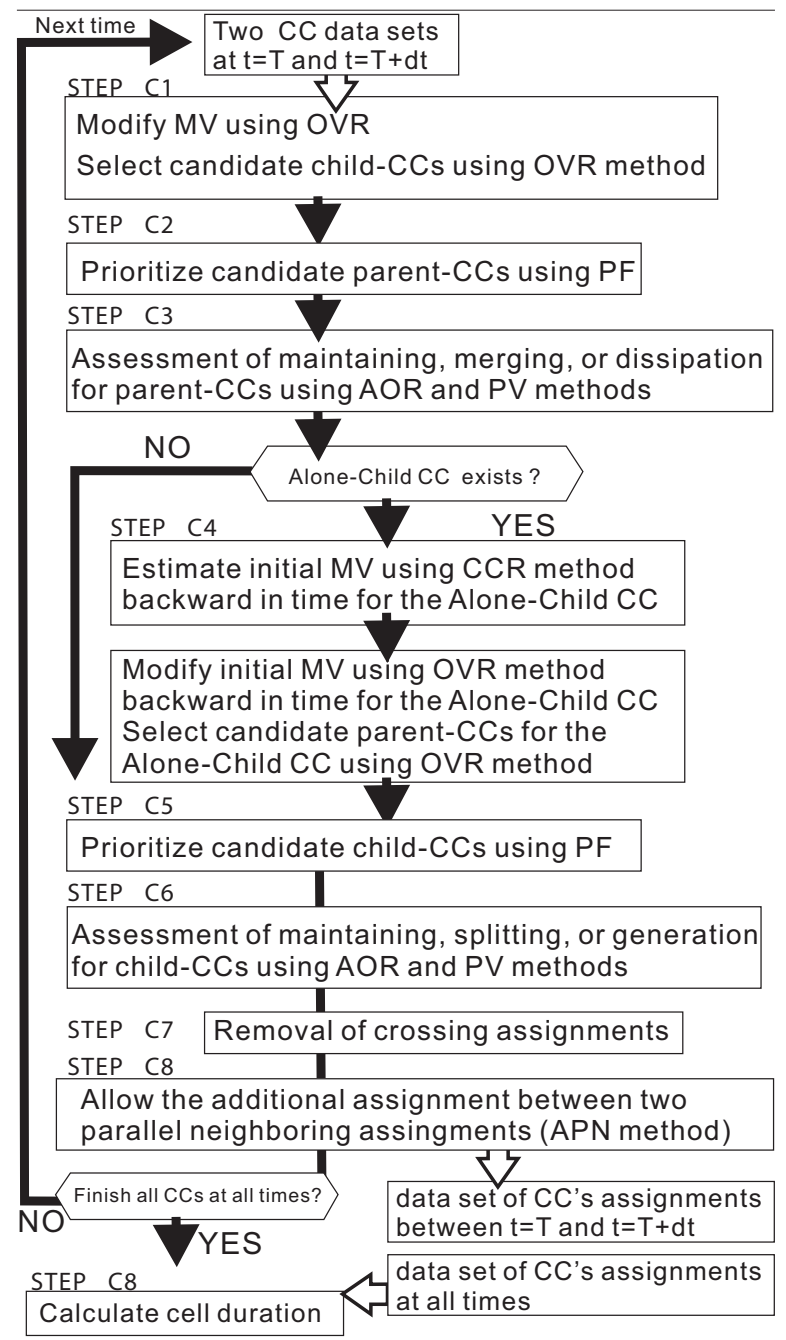

crossing angle.

The APN method would recover assignments that are rejected by the $A O R$ and PV methods, especially in situations where convective cells are located close together.

After completing the tracking procedures between $\mathrm{t}=$ $\mathrm{T}$ and $\mathrm{t}=\mathrm{T}+d t$, tracking is conducted between $\mathrm{t}=\mathrm{T}+d t$ and $\mathrm{t}=\mathrm{T}+2 d t$. This cycle is repeated throughout the observation period. Finally, AITCC calculates the lifetime of each CC (Step C9) and provides the temporal evolution of each $\mathrm{CC}$ throughout its life cycle. The lifetime of $\mathrm{CC}$ is calculated as following; $L=\left(N_{p}+\right.$ $1) \times d t$. Where, $L$ is lifetime, $N_{p}$ is the number of the primary assignment, and $d t$ is time resolution (Fig. 6). For instance, the lifetime of cell without assignment (instantaneous cell) is $d t$.

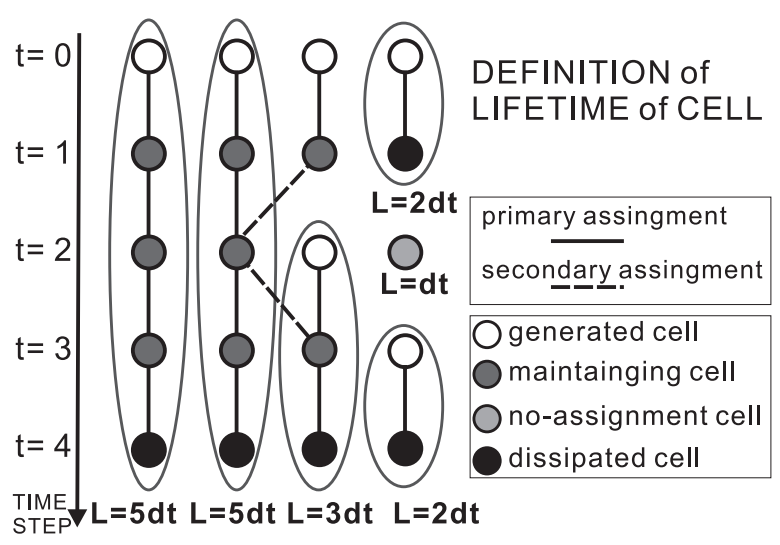

Fig. 6. Schematic sketch of the definition of cell's lifetime in AITCC. Color of circle indicates cell's state (black: dissipated; white: newly generated; gray: maintaining; and light-gray: no assignment). The solid line indicates primary assignment between two successive scans. The dashed line indicates secondary assignment such as merging or splitting. Lifetime of CC (denoted as "L") is defined as the product of the number of primary assignment and time resolution (dt). The lifetimes of 6 cells are defined in the present case.

\section{Evaluation of AITCC performance}

\subsection{Evaluation of the tracking performance of AITCC using observational dataset}

To evaluate the tracking performance of AITCC, cell assignments between the previous scan and a recent scan are visually compared with manual assignments. The verification set for each assignment is carefully determined through visual inspection of the three-dimensional radar reflectivity data. The following set of verification rules for the manual assignment between the two cells (e.g., cell A in the previous scan and cell $B$ in the next scan) is employed:

1. Cells A and B have a maximum reflectivity of at least $30 \mathrm{dBZ}$.

2. The shape and size of cell A are most similar to those of cell B among cells within $10 \mathrm{~km}$ of cell $A$ at a height of $3 \mathrm{~km}$ ASL as determined by visual inspection using a contour interval of $0.5 \mathrm{dBZ}$.

3. The value and location of the maximum reflectivity of cell A are most similar to those of cell B among cells within $10 \mathrm{~km}$ of cell A at a height of $3 \mathrm{~km}$ ASL as determined by visual inspection.

4. When a cell merging (splitting) takes place at a height of $3 \mathrm{~km} \mathrm{ASL}$, the peak locations of reflec- 
Table 5. List of experiments.

\begin{tabular}{cccccc}
\hline experiment number & experiment name & Use of AOR & Use of PV & Use of RC & Use of APN \\
\hline 1 & CNTL & Yes & Yes & Yes & Yes \\
2 & NAPN & Yes & Yes & Yes & No \\
3 & NRC & Yes & Yes & No & Yes \\
4 & NRC_NAPN & Yes & Yes & No & No \\
5 & NPV & Yes & No & Yes & Yes \\
6 & NPV_NAPN & Yes & No & Yes & No \\
7 & NPV_NRC & Yes & No & No & Yes \\
8 & NPV_NRC_NAPN & Yes & No & Yes & No \\
9 & NAOR & No & No & Yes & No \\
10 & NAOR_NAPN & No & No & No & Yes \\
11 & NAOR_NRC & No & No & No & No \\
12 & NALL & No & No & & \\
\hline
\end{tabular}

tivity at higher levels are investigated. If we find two distinct peaks over the merged region at any height above $3 \mathrm{~km} \mathrm{ASL}$, the cell merging (splitting) is accepted.

The cell assignment is allowed if all these conditions are satisfied. 1268 cell assignments were allowed in the verification data set. For isolated CCs, manual tracking is very easy. However, it becomes difficult for a cluster of multiple CCs, but in most of the present cases, the relative location of such CCs did not significantly change during $6 \mathrm{~min}$, thus we believe that visual inspection can provide reasonable assignments.

For quantitative evaluations, we employed the Critical Success Index (CSI), False Alarm Rate (FAR), and Probability of Detection (POD), as described by equations $6-8$, respectively.

$$
\begin{aligned}
& C S I=\frac{H}{H+F+M} \\
& F A R=\frac{F}{H+F} \\
& P O D=\frac{H}{H+M}
\end{aligned}
$$

where $H$ is the number of correct assignments (i.e., the assignment by AITCC is also found in the verification data set), $M$ is the number of missed assignments (i.e., the assignment by AITCC is not found, although it is found in the verification dataset), $F$ is the number of incorrect assignments (i.e., the assignment by AITCC is found, although it is not found in the verification dataset). The sum of $\mathrm{H}$ and $\mathrm{M}$ corresponds to the 1268 cell assignments in the verification data set.

The CSI, FAR, and POD were evaluated for AITCC with various options (e.g., AOR, PV, RC, and APN methods) in the cell tracking to clarify which methods were effective. Table 5 lists the experiments performed as part of this analysis. CNTL is the control run, which uses all the options available in AITCC. The first letter "N" of each experiment name indicates "no use" and the following letters indicate the option (e.g., "NAOR" indicates no use of the $A O R$ method). "NALL" indicates no use of all options. In AITCC, the PV method is applied following application of the $A O R$ method. Therefore, the PV method is not implemented if the $A O R$ method is not employed.

Before undertaking a quantitative comparison of the scores yielded by the experiments, cell assignments from 0318 LST to 0342 LST (as an example) were compared to highlight the difference in the assignments for each experiment.

Cell assignments by manual tracking are shown in Fig. 7. For simplicity, we tracked cells within the area outlined by the rectangle in Fig. 7a. New convective cells (cells D and E in Fig. 7b, and cell G in Fig. 7c) developed and formed a cell group on the southwest side of older convective cells. As shown in Fig. 7e, an old cell (cell B) dissipated when the other cells (cells A and I) developed in the southwest side of the cell. It was relatively easy to track the cells by human eye because each convective cell within the rainband had a distinct peak and constant movement vector.

Figure 8 shows the result of CNTL experiment for which the tracking is in good agree ment with that in Fig. 7. Note that cell I was first detected at 0336 LST because it was smaller than $4 \mathrm{~km}^{2}$ at 0330 LST.

The NAPN experiment (Fig. 9) shows a similar result to the CNTL experiment except that the assignments between cell A at 0330 LST and cell A2 at 0336 LST, and between cell E at 0324 LST and cell E2 at 0330 LST, were not made. Through comparison of the 

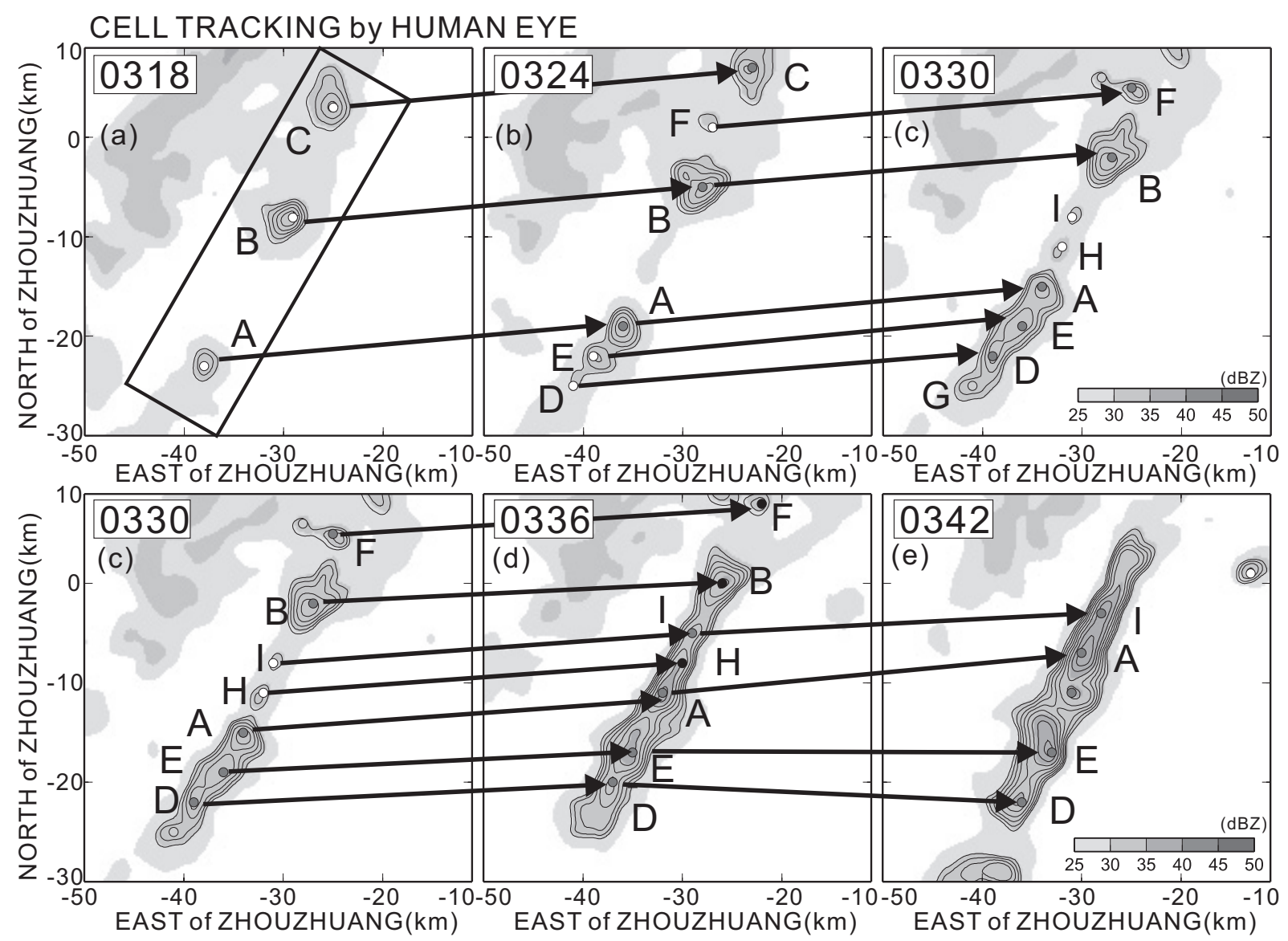

Fig. 7. Observed reflectivity at a height of $3 \mathrm{~km} \mathrm{ASL} \mathrm{from} 0318$ to 0342 LST on 24 June 2001 describing the cells which are marked by identity numbers in the area outlined by the rectangle. Cell tracking was performed by subjective visual inspection. Solid arrow indicates major assignment. Small circles indicate the location of the reflectivity peak. The color of circle indicates cell's state (black: dissipated; white: newly generated; gray: maintaining; and light-gray: no assignment).

CNTL and NAPN experiments, the APN method made up the definit in assignments in the case that cells were aligned within the rainband.

The NRC experiment yielded the same results as the CNTL experiment because there were no crossing assignments after application of the $A O R$ and PV methods (data not shown). Similarly, the NRC_NAPN experiment yielded the same results as the NAPN experiment (data not shown). Therefore, the RC method has little effect on the removal of incorrect merging or splitting assignments if the $A O R$ and $\mathrm{PV}$ method are used in advance.

The NPV experiment (Fig. 10) yielded a splitting at 0324 LST and mergings at 0330 LST and 0336 LST. The NPV_NRC, NPV_NAPN, and NPV_NRC_NAPN experiments showed similar assignments to those in the NPV experiment. The NPV_NRC experiment (data not shown) yielded an assignment between cell $\mathrm{A}$ at 0324 LST and cell E at 0330 LST, in addition to the assignments in Fig. 10. However, the additional assignment crosses another assignment. Similarly to the NAPN experiment, the NPV_NAPN experiment (data not shown) deleted the assignment of cell A between 0330 LST and 0336 LST from Fig. 10. The NPV_NRC NAPN experiment added an assignment between cell $A$ at 0324 LST and cell E at 0330 LST, and deleted the assignment of cell A between 0330 LST and 0336 LST from Fig. 10. As seen in the NPV experiment, the PV method restricted the merging and splitting of neighboring cells if the assignment vector was different from that of the neighbor (e.g., the assignment from cell E to cell $\mathrm{A}$ in Fig. 10b, and assignment from cell $\mathrm{G}$ to cell 

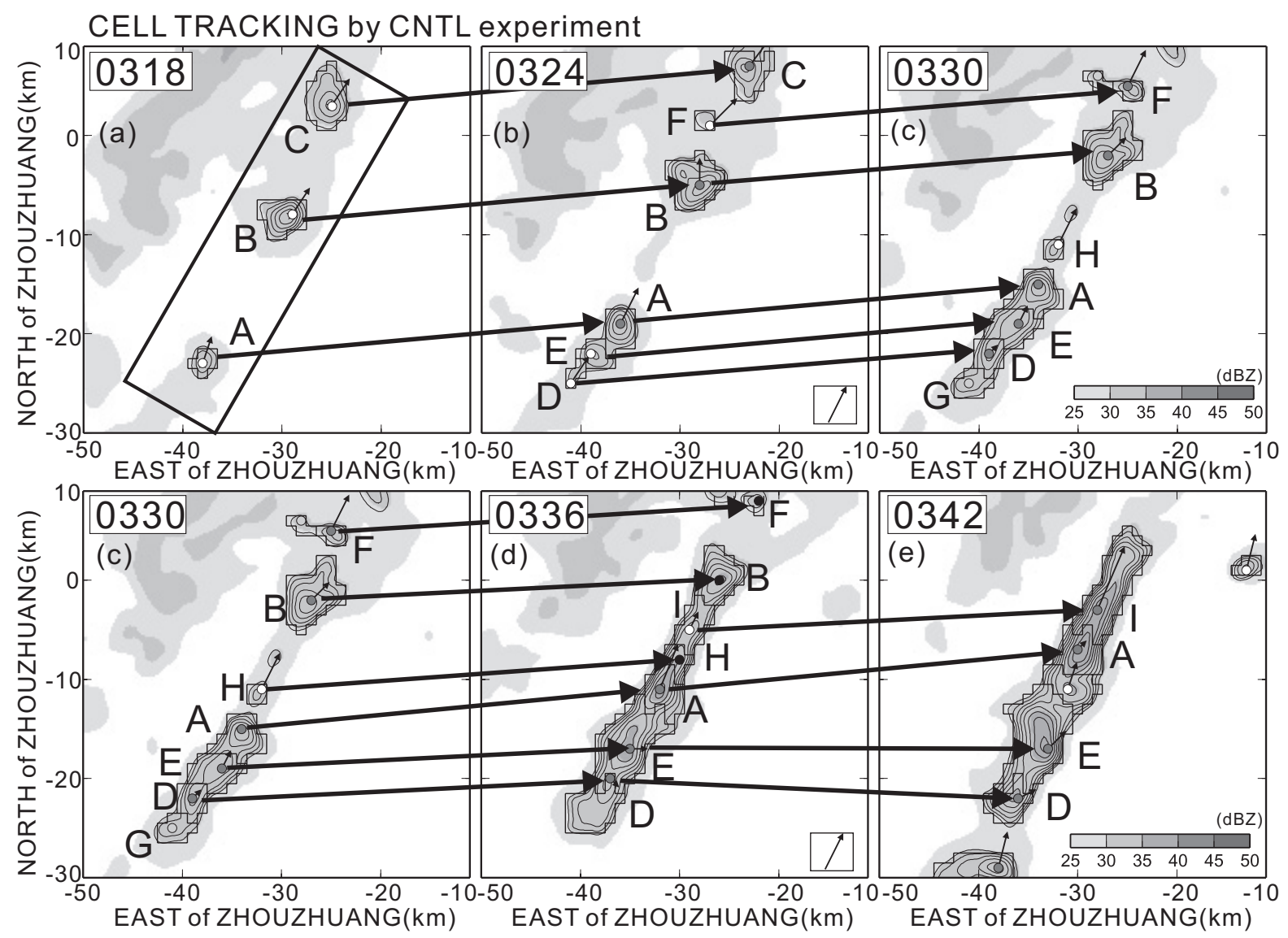

Fig. 8. Same as Fig. 7, but cell tracking was performed by AITCC with all options (CNTL experiment). The boundary of cell is outlined by thin line. Small arrow assigned to each cell indicates cell's motion. The arrow in the lower-right corner indicates movement vector of cell group.

D in Fig. 10c).

The NAOR experiment (Fig. 11) and NALL experiment (Fig. 12) yielded many merging and splitting events. None of the assignments in the NAOR experiment crossed each other, but some were crossed in the NALL experiment. Application of the AOR method resulted in a marked reduction in the number of assignments between neighboring cells by considering the conservation of the total area of cells.

The NAOR_NAPN experiment (data not shown) provided the same assignments as those in NAOR because the condition for application of the APN method was not satisfied when the neighbor assignments are crowded. The NAOR_NRC experiment (data not shown) provided the same assignments as those in the NALL experiment. In the case that the $A O R$ method was not applied, the RC method was effective in reducing the number of incorrect assignments.
These comparisons revealed that : 1) the $A O R$ method was the most effective in limiting the assignments based on the conservation of area; 2) the PV method assisted the AOR method in reducing the number of assignments with different directions from those of neighbors; 3) the RC method was less effective than the $A O R$ and $\mathrm{PV}$ methods in reducing the number of incorrect assignments, although the RC method does ensure no crossing assignments; and 4) the APN method made up the assignments after application of the $A O R$ and PV methods.

Table 6 compares the values of CSI, FAR, and POD for each experiment. The highest CSI (71.4\%) and the lowest FAR values $(9.6 \%)$ were obtained in the CNTL experiment. The lowest CSI (52.1\%), the highest FAR (46.7\%), and the highest POD values (95.7\%) were obtained in the NALL and NAOR NRC experiments.

Identical results were obtained in the NAOR and 

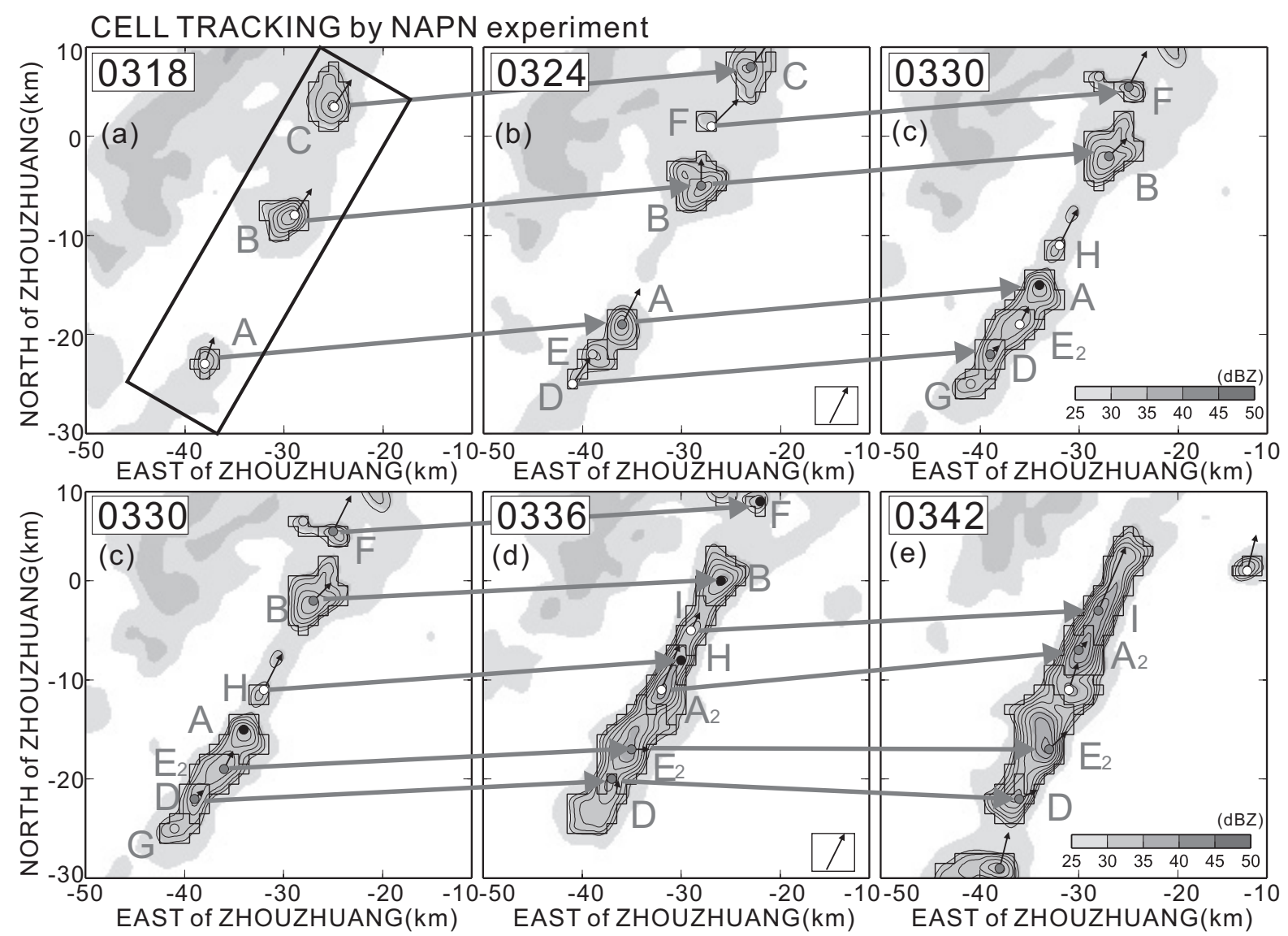

Fig. 9. Same as Fig. 8 but for NAPN experiment. Gray arrow and alphabet indicate same assignments and cells as those in CNTL experiment (Fig. 8)

NAOR_NAPN experiments, and in the NAOR_NRC and NALL experiments. This arose because the condition for the application of the APN method was not satisfied when the $A O R$ method was not applied as explained earlier.

The high value of POD in the NALL (NAOR NAPN) experiment is attributed to the high number of correct assignments and the small number of missed assignments compared with the CNTL experiment. However, the number of incorrect assignments in the NALL (NAOR NAPN) experiment is significantly higher than in the CNTL experiment, resulting in a high FAR value.

The AOR method increased the value of CSI by $17.0 \%$ on average compared with two experiments that used the same options but not the AOR option (e.g., NPV and NAOR experiments, and the other three pairs in Table 5). Similar comparisons showed that the PV, $\mathrm{RC}$, and APN methods yielded average CSI increases of
$0.8 \%, 0.9 \%$, and $0.4 \%$, respectively. Application of the $A O R, \mathrm{PV}, \mathrm{RC}$, and APN methods resulted in reductions of the average FAR value by $33.2 \%, 2.6 \%, 1.2 \%$, $0.1 \%$, respectively. Application of the $A O R, \mathrm{PV}$ and $\mathrm{RC}$ methods resulted in the reductions of the average POD value by $17.8 \%, 1.0 \%$, and $0.1 \%$, respectively. The APN method yielded an average increase of $0.5 \%$.

These quantitative comparisons of CSI, FAR, and POD reveal that: 1) all options increased CSI and decreased FAR; 2) the AOR method made the largest contribution to the improvement of CSI and FAR; 3) the PV and RC methods made similar contributions to the improvement of CSI, but the PV method made a larger contribution to the improvement of FAR; and 4) the APN method made the smallest contribution to the improvements of CSI and FAR, but only APN resulted in improved POD. 

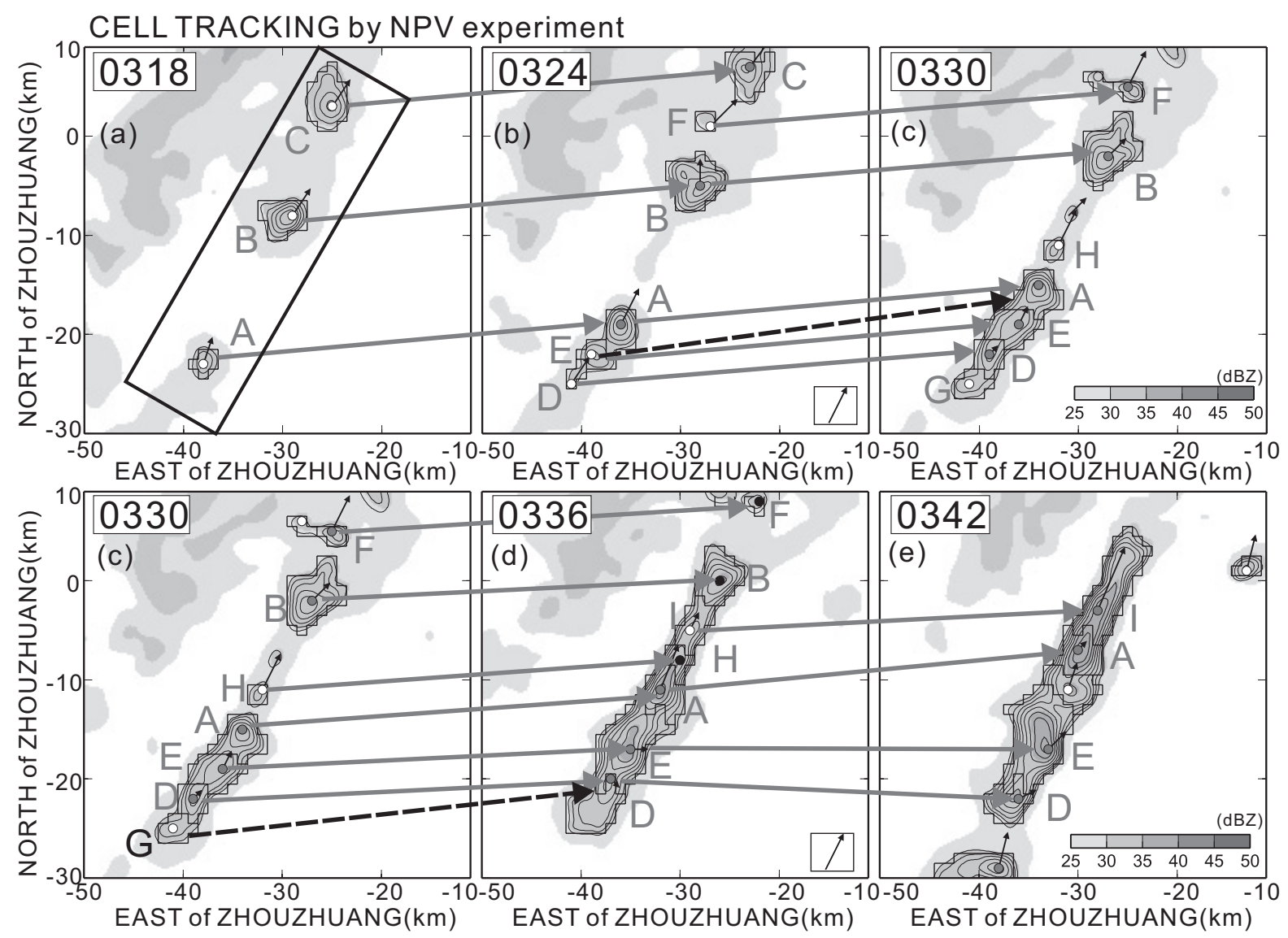

Fig. 10. Same as Fig. 8 but for NPV experiment. Gray arrow and alphabet indicate same assignments and cells as those in CNTL experiment (Fig. 8), while black arrow and alphabet indicate different ones from CNTL experiment. Solid arrow indicates major assignment, and dashed arrow indicates secondary assignment such as merging or splitting.

\section{Discussions}

The AITCC tracking algorithm showed a $71.4 \%$ critical success index (CSI) for cell assignments from the previous scan to the recent scan. We demonstrated that all options available in AITCC improved the CSI value. Especially, the scheme that assumes the conservation of total cell area when merging or splitting occur significantly improved the CSI value and reduced the FAR value. However, the CSI value with full options (CNTL experiment) did not exceed those values reported in the previous tracking algorithms; e.g., 94\% reported by Handwerker, 2002 and $84 \%$ by Kyznarova and Novak, 2009 in TRACE3D, and $88 \%$ by Kyznarova and Novak, 2009 in CELLTRACK. As noted by Wilson et al. (1999), a comparison of different tracking algorithms is invalid if they use different objects to track and aim for different goals. In fact, the definition of a convective cell (CC) in AITCC (at least $30 \mathrm{dBZ}$ ) differs from that in TRACE3D (at least $45 \mathrm{dBZ}$ ) and in CELLTRACK (at least $44 \mathrm{dBZ}$ ) as explained above. AITCC was first developed for the statistical analysis of non-severe convective cells in the Meiyu frontal region. For severe convective cells in other environments, higher thresholds are available and would have a positive effect on the quality of the tracking routines. In fact, we evaluated convective cells that exceed 35 and $40 \mathrm{dBZ}$ using the present observational dataset and obtained CSIs of $76.3 \%$ and $88.2 \%$, respectively. However, the numbers of sampled cell assignments were reduced by $83 \%$ and $98 \%$ respectively, compared with the number of sampled cell assignments for convective cells that exceed $30 \mathrm{dBZ}$. Although there is no previous report on the CSI, FAR, and POD values of the cell assignment for the weak convective cells (30-40 dBZ), we could not show the superiority of 

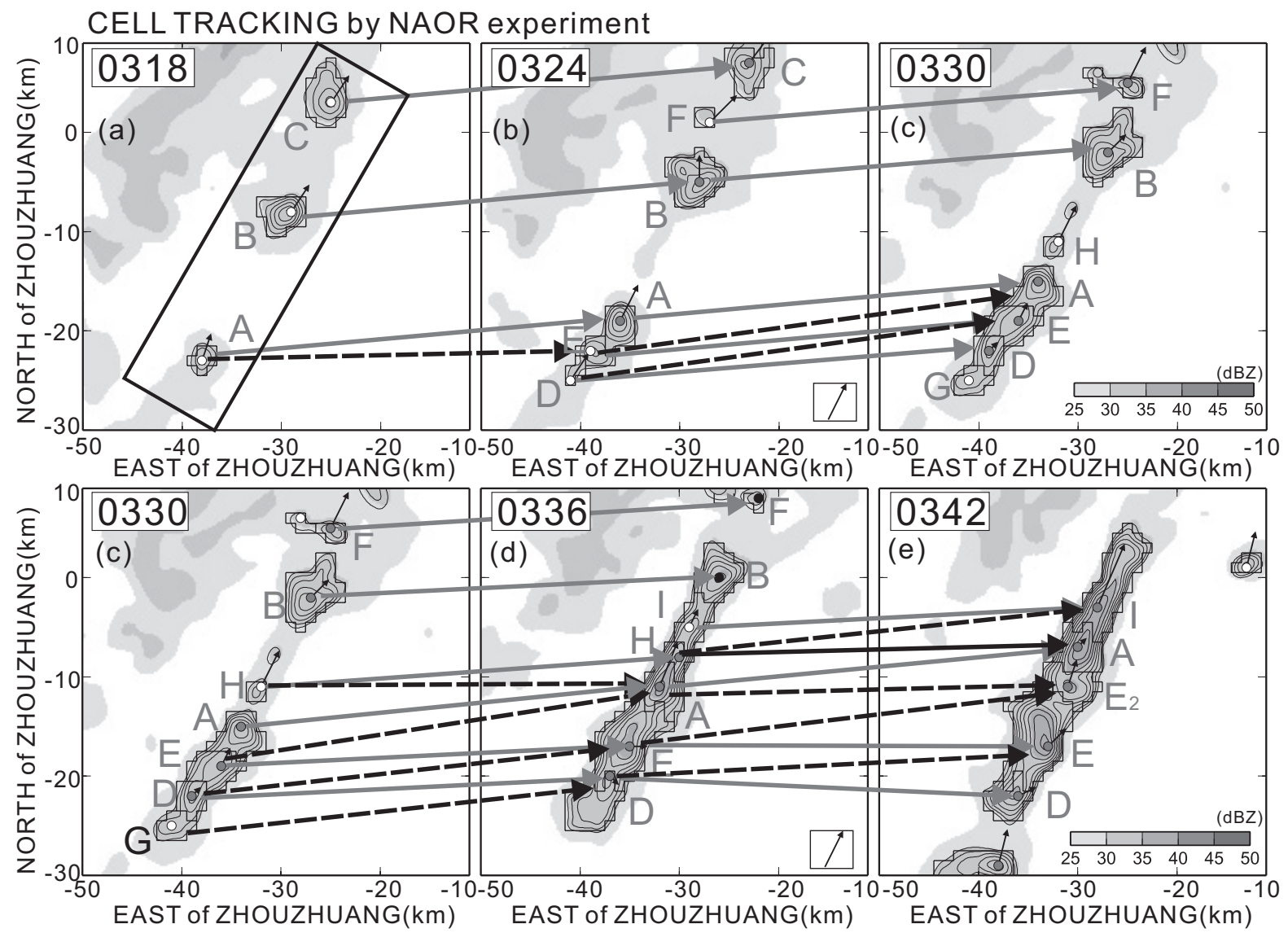

Fig. 11. Same as Fig.10 but for NAOR experiment.

ATICC over the previous algorithms. However, the small value of FAR $(9.6 \%)$ in ATICC would not lead to an overestimation of the lifetime of convective cells.

To further improve the value of CSI for non-severe CCs or CCs in their developing stage, a finer temporal resolution of input data is considered the most important factor. Handwerker (2002) reported that the CSI of cell tracking with a temporal resolution of $5 \mathrm{~min}$ is larger than that with a resolution of $10 \mathrm{~min}$. In this discussion, we examine the dependency of the AITCC tracking performance on the temporal resolution of the input dataset.

\subsection{Comparison with tracking at a fine temporal resolution}

The main advantage of using numerical simulation data is that we can obtain the time evolution of a convective cell for any time interval. In this study, we compared the tracking performance using time resolutions of $1 \mathrm{~min}, 5 \mathrm{~min}$, and $10 \mathrm{~min}$ (hereafter, 1-min tracking, 5-min tracking, and 10-min tracking).

The total numbers of simulated cells detected in 1-min, 5-min, and 10-min tracking were 15977, 3134, and 1517 respectively between 0100 LST and 0600 LST. The numbers include multiple counts of a given cell at different time points.

Figure 13a-13f shows an example for the time evolution of reflectivity during $5 \mathrm{~min}$ with a interval of 1-min. Almost all of the assignments from 5-min tracking (Figs. 13a, g) are the same as those for 1-min tracking (Figs. 13a, f), except that the cell A in Fig. 13g was replaced by a new cell V in Fig. 13f. The cell A dissipated in the 1-min tracking (Fig. 13b). However, cell A was regarded as being maintained in the 5-min tracking. Thus, when using 5-min resolution, there is a likelihood of an incorrect connection to the new cell.

Table 7 compares the values of CSI, FAR, and POD for the experiments with three temporal resolutions. The highest CSI and the lowest FAR values were obtained in 1-min tracking. As the temporal resolution 

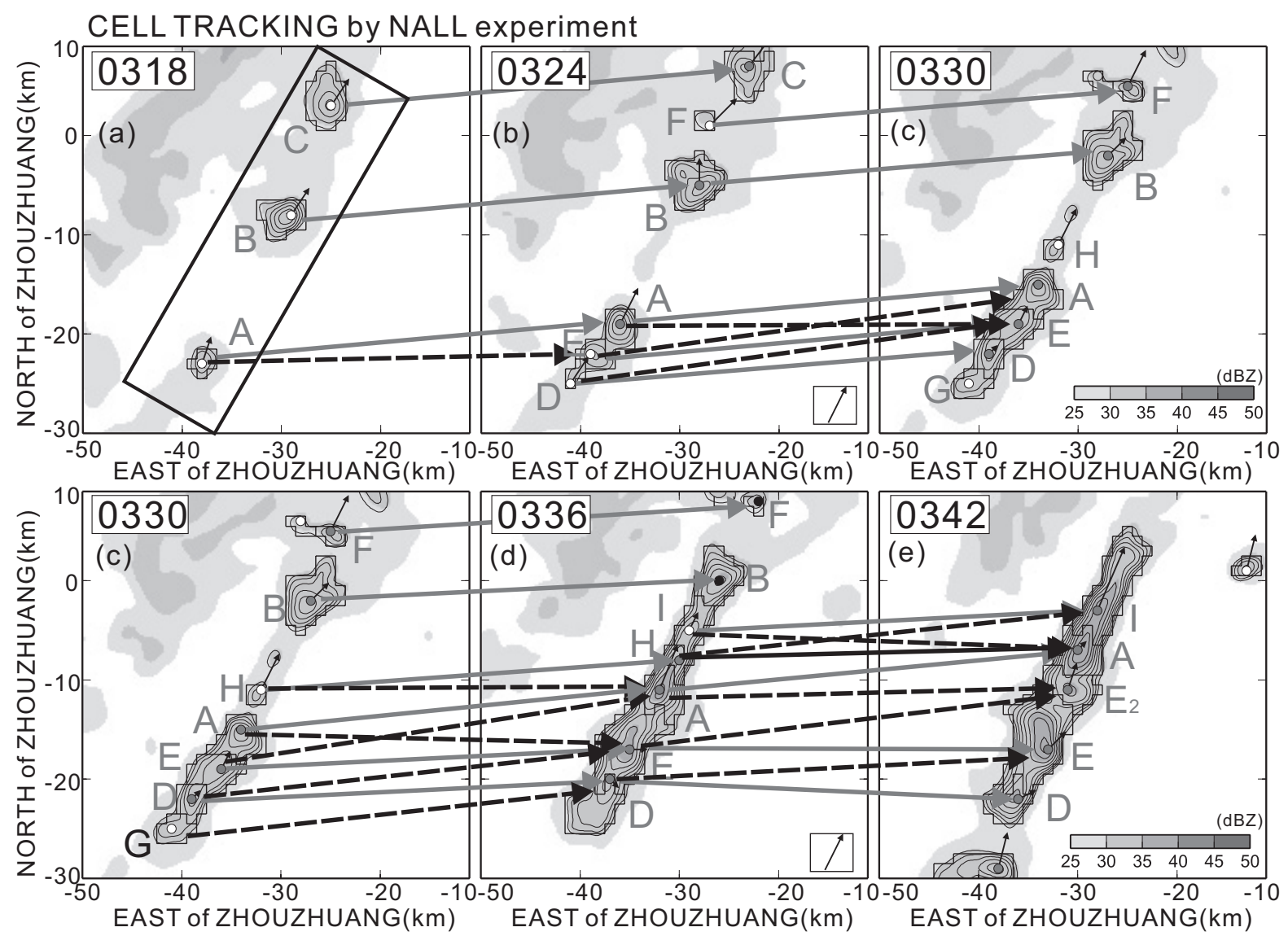

Fig. 12. Same as Fig.10 but for NALL experiment.

became longer, the values of CSI and POD decreased, and the value of FAR increased. These comparisons indicate that a cell tracking algorithm can be improved by updating the input data frequently, in addition to improving the algorithm itself. However, a single volume scan generally takes $5-10$ min using current technology, but this time will be reduced using the high temporal resolution of next-generation phased array radars (Heinselman and Torres 2011). Future development of the AITCC tracking algorithm should include a further investigation of the dependency of tracking performance on time resolution using a fine-temporal-resolution dataset obtained from nextgeneration phased array radar or from a sector volume scan (Junyent et al. 2010).

\section{Conclusions}

We developed a new Algorithm for Identification and Tracking of Convective Cells (AITCC) and for tracing the temporal evolution of cells from the devel- oping to the dissipating stages. The tracking algorithm was designed to correctly handle cell merging and splitting, even when the cells are well organized and located close together. The algorithm combines the constant and adaptive threshold methods to define a cell as an enclosed region of more than $30 \mathrm{dBZ}$ with a single reflectivity core, thereby enabling statistical analysis. AITCC has sophisticated merging and splitting schemes in two-way tracking, both forward and backward in time. Forward tracking determines the status of cells (i.e., dissipating, maintained, or merging) from the previous radar scan, while backward tracking determines the status of cells (newly born, maintained, or splitting) in the most recent scan. The assignment of "splitting" or "merging" is based on the accumulated occupation ratio $(A O R)$ method and the principal vector (PV) method. The AOR method conserves the total area of the cell during merging or splitting, while the PV method maintains the relative locations of cells between successive scans. The 
Table 6. Correct assignments, missed assignments, incorrect assignments and CSI, FAR, and POD values for each experiment using the observational dataset. The highest values of CSI and POD, and the lowest value of FAR are marked in bold.

\begin{tabular}{|c|c|c|c|c|c|c|}
\hline experiment name & $\begin{array}{c}\text { Correct } \\
\text { assignments }\end{array}$ & $\begin{array}{c}\text { Missed } \\
\text { assigments }\end{array}$ & $\begin{array}{c}\text { Incorrect } \\
\text { assignments }\end{array}$ & $\begin{array}{l}\text { CSI } \\
(\%)\end{array}$ & $\begin{array}{l}\text { FAR } \\
(\%)\end{array}$ & $\begin{array}{l}\text { POD } \\
(\%)\end{array}$ \\
\hline CNTL & 979 & 289 & 104 & 71.4 & 9.6 & 77.2 \\
\hline NAPN & 969 & 299 & 104 & 70.6 & 9.7 & 76.4 \\
\hline NRC & 979 & 289 & 114 & 70.8 & 10.4 & 77.2 \\
\hline NRC_NAPN & 969 & 299 & 114 & 70.6 & 10.5 & 76.4 \\
\hline NPV & 990 & 278 & 134 & 70.6 & 11.9 & 78.1 \\
\hline NPV_NAPN & 982 & 286 & 134 & 70 & 12 & 77.4 \\
\hline NPV_NRC & 990 & 278 & 145 & 70.1 & 12.8 & 78.1 \\
\hline NPV_NRC_NAPN & 982 & 286 & 145 & 69.5 & 12.9 & 77.4 \\
\hline NAOR & 1209 & 59 & 965 & 54.1 & 44.4 & 95.3 \\
\hline NAOR_NAPN & 1209 & 59 & 965 & 54.1 & 44.4 & 95.3 \\
\hline NAOR_NRC & 1214 & 54 & 1063 & 52.1 & 46.7 & 95.7 \\
\hline NALL & 1214 & 54 & 1063 & 52.1 & 46.7 & 95.7 \\
\hline
\end{tabular}
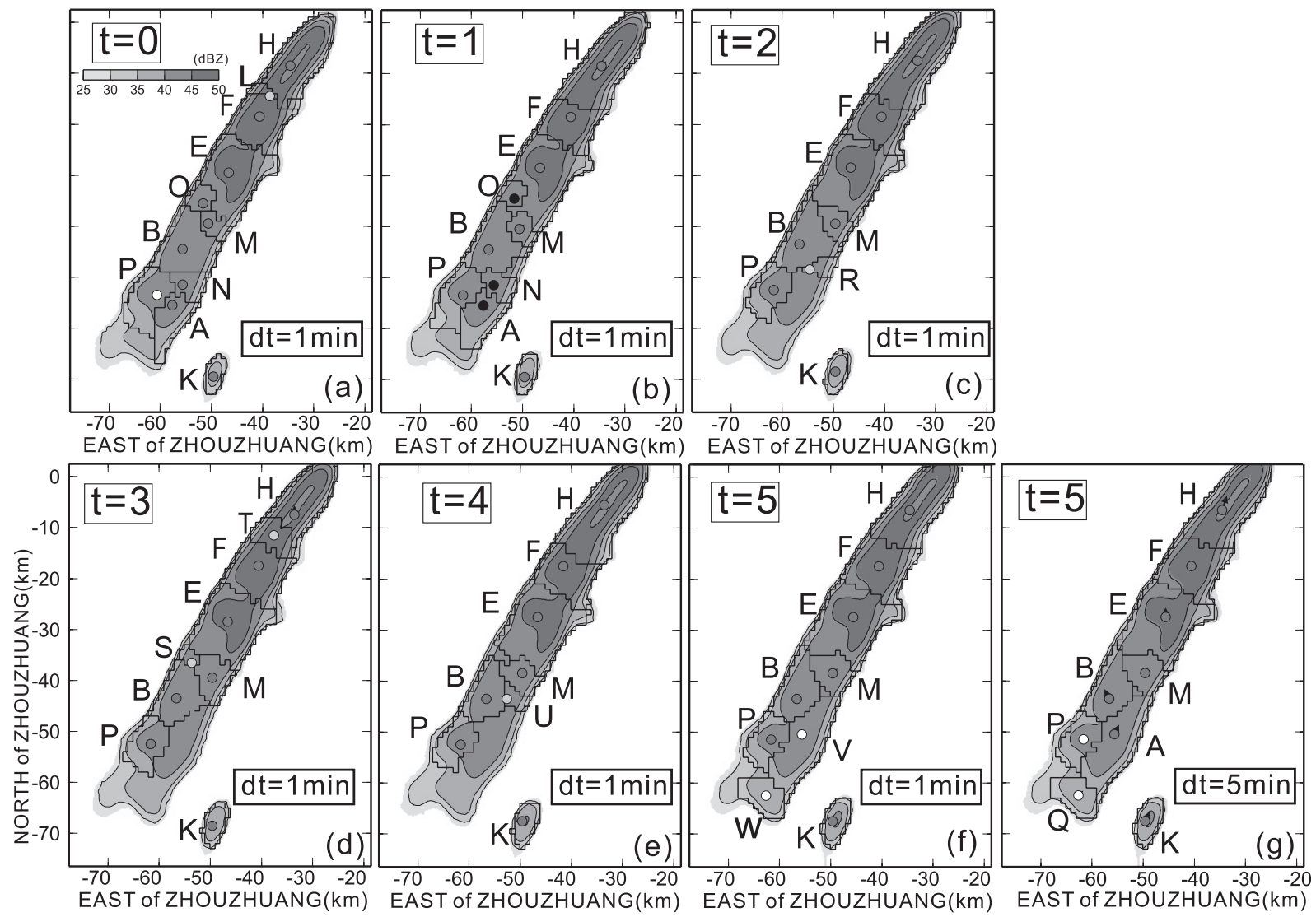

Fig. 13. An example for the time evolution of simulated reflectivity at $3 \mathrm{~km}$ ASL during 5 min with a interval of 1-min, describing cells tracked by 1-min tracking. Final panel (Fig. 13g) indicates the cell number by 5-min tracking. The same alphabet in different time indicates identified cell. Small circles indicate the location of the reflectivity peak. The color of circle indicates cell's state as in Fig. 6. 
Table 7. As for Table 6 but for the CNTL experiment using the numerical dataset with 1-min, 5-min, and 10-min intervals.

\begin{tabular}{ccccccc}
\hline time interval & $\begin{array}{c}\text { Correct } \\
\text { assignments }\end{array}$ & $\begin{array}{c}\text { Missed } \\
\text { assigments }\end{array}$ & $\begin{array}{c}\text { Incorrect } \\
\text { assignments }\end{array}$ & $\begin{array}{c}\text { CSI } \\
(\%)\end{array}$ & $\begin{array}{c}\text { FAR } \\
(\%)\end{array}$ & $\begin{array}{c}\text { POD } \\
(\%)\end{array}$ \\
\hline $1 \mathrm{~min}$ & 11892 & 812 & 35 & 93.4 & 0.3 & 93.6 \\
$5 \mathrm{~min}$ & 2068 & 154 & 41 & 93.1 & 1.9 & 93.1 \\
$10 \mathrm{~min}$ & 964 & 159 & 91 & 79.4 & 8.6 & 85.8 \\
\hline
\end{tabular}

$A O R$ and PV methods prevent cells from merging or splitting incorrectly, especially in situations where convective cells are located close together.

The performance of AITCC in tracking was evaluated in an analysis of 2004 convective cells and in 1268 cell assignments observed between 0100 LST and 0900 LST on 24 June 2001 near Shanghai. The Critical Success Index (CSI), False Alarm Rate (FAR), and Probability of Detection (POD) were evaluated for AITCC with the above options in the cell tracking to clarify which methods were effective in providing a correct cell assignment. The AOR method was the most effective method in limiting the incorrect assignments and made the largest contribution to improving CSI and FAR, indicating that the conservation of total cell area is the most important factor to improve cell assignment in situations where convective cells are located close together. The PV and RC methods assisted the $A O R$ method in reducing the number of incorrect assignments. The APN method made the smallest contribution to improving CSI and FAR, but recovered missed assignments. AITCC with these full options yielded CSI, FAR, and POD of 71.4\%, 9.6\%, and $77.2 \%$, respectively. The small value of FAR $(9.6 \%)$ would not lead to an overestimation of the lifetime of convective cells.

To further improve these scores, this study proposed a further investigation of the dependency of tracking performance on time resolution using a fine-temporal-resolution dataset obtained from next-generation phased array radar or from a sector volume scan. Finally, it should be noticed that AITCC is expected to provide a powerful tool with which to understand the statistical features of non-severe convective cells embedded within a mesoscale convective system or convective cells in their developing stage.

\section{Acknowledgments}

We are grateful to Dr. T. Kato (Meteorological Research Institute) for his fruitful discussions. Special thanks to extended to two anonymous reviewers for their useful comments. All the figures were created using Generic Mapping Tools. The numerical simu- lation was performed on the SGI Altix 4700 at the National Research Institute for Earth Science and Disaster Prevention (NIED), Japan.

\section{References}

Chen, J., H. Uyeda, and D.-I. Lee, 2003: A method using radar reflectivity data for the objective classification during the Baiu season. J. Meteor. Soc. Japan, 81, 229-249.

Churchill, D. D., and R. A. Houze, Jr., 1984: Mesoscale updraft magnitude and cloud-ice content from the ice budget of the stratiform region of a tropical cloud cluster. J. Atmos. Sci., 41, 1717-1725.

Cressman, G., 1959: An operational objective analysis system. Mon. Wea. Rev., 87, 367-374.

Dixon, M., and G. Wiener, 1993: TITAN: Tunderstorm Identification, Tracking, Analysis, and Nowcasting- A radar-based methodology. J. Atmos. Oceanic Tech., 10, 785-797.

Doviak, R. J., and D. S. Zrnić, 1993: Doppler raedar and weather observations. Academic Press, 880pp.

Fujiwara, M., 1965: Raindrop-size distribution from individual storms. J. Atmos. Sci., 22, 585-591.

Gekat, F., P. Meischner, K. Friedrich, M. Hagen, J. Koistinen, D. B. Michelson, and A. Huuskonen, 2003: Weather Radar. Springer, chapter 1, 1-35.

Geng, B., H. Yamada, K. K. Reddy, H. Uyeda, and Y. Fujiyoshi, 2004: An observational study of the depelopment of development of a rainband on a Meiyu front causing heavy rainfall in the downstream region of the Yangtze river. J. Meteor. Soc. Japan, 82, 1095- 1115.

Handwerker, J., 2002: Cell tracking with TRACE3D-a new algorithm. Atmos. Res., 61, 15-34.

Hauser, D., and P. Amayenc, 1986: Retreaval of cloud water and water vapor contents from Doppler radar data in a tropical squall line. J. Atmos. Sci., 43, 823-838.

Heinselman, P. L., and S. M. Torres, 2011: High-temporal-resolution capabilities of the national weather radar testbed phased-array radar. J. Appl. Meteor. Climatol., 50, 579-593.

Hering, A. M., C. Morel, G. Galli, S. Sénési, and M. Boscacci, 2004: Nowcasting thunderstorms in the Alpine region using a radar based adaptive thresholding scheme. Proceedings of Third European Conference on Radar in Meteorology and Hydrology, Visby, Island of Gotland, Sweden, 206-211. 
Hilgendorf, E. R., and R. H. Johnson, 1998: A study of the evolution of mesoscale convective systems using WSR-88D data. Wea Forecasting, 13, 437-452.

Houze, R. A., Jr., B. F. Smull, and P. Dodge, 1990: Mesoscale organization of springtime rainstorms in Oklahoma. Mon. Wea. Rev., 118, 613-654.

Johnson, J. T., P. L. MacKeen, A. Witt, and E. D. Mitchell, 1998: The strom cell identification and tracking algorithm: An enhanced WSR-88D algorithm. Wea. Forecasting, 13, 263-276.

Junyent, F., V. Chandraseker, D. McLaughlin, E. Insanic, and N. Bharadwaj, 2010: The CASA integrated project I: Network radar system. J. Atmos. Oceanic Technol., 27, 61-78.

Kim, D. S.-., M. Maki, and D. I. Lee, 2010: Retrieval of three-dimensional raindrop size distribution using x-band polarimetric radar data. J. Atmos. Oceanic Technol., 27, 1265-1285.

Kyznarova, H. and P. Novak, 2009: CELLTRACK -Convective cell tracking algorithm and its use for deriving life cycle characteristics. Atmos. Res., 93, 317-327.

Murakami, M., 1990: Numerical modelilng of dynamical and microphysical evolution of an isolated convective cloud the 19 july 1981 ccope cloud. J. Meteor. Soc. Japan, 68, 107-128.

Murakami, M., T. L. Clark, and W. D. Hall, 1994: Numerical simulations of convective snow clouds over the Sea of Japan. J. Meteor. Soc. Japan, 72, 43-62.

Orlanski, L., 1975: A rational subdivision of scale for atmosperic processes. J. Appl. Meteor, 56, 527-530.

Parker, M. D., and R. H. Johnson, 2000: Orgranizational modes of midlatitude mesoscale convective sysmtems. Mon. Wea. Rev., 128, 3413-3436.

Rinehart, R. E., and E. T. Garvey, 1978: Three-dimensional storm motion detection by conventional weather radar.
Nature, 273, 287-289.

Rossenfeld, D., 1987: Objective method for analysis and tracking of convective cells as seen by radar. J. Atmos. Oceanic Technol., 4, 422-434.

Roux, F., 1985: Retreaval of thermodynamic fields from multiple-Doppler radar data using the equations of motion and the thermodynamic equation. Mon. Wea. Rev., 113, 2142-2157.

Saito, K., T. Kato, H. Eito, and C. Muroi, 2001: Documentation of meteorological research institute numerical prediction division unified nonhydrostatic model. Technical Report 42, Meteorological Research Institute, Japan, 133 pp.

Steiner, M., R. A. Houze, Jr., and S. E. Yuter, 1995: Climatological characterization of three-dimensional Storm structure from operational radar and rain gauge data. $J$. Appl. Meteor., 34, 1978-2007.

Tsuboki, K., and A. Sakakibara, 2001: CReSS user's guide (in japanese). $2 \mathrm{~d}$ ed. 210pp.

Tsuboki, K., and A. Sakakibara, 2002: Large-scale parallel computing of Cloud Resolving Storm Simulator. High Performance Computing, Springer, H. P. Zima et al. Eds, 243-259.

Wilson, J. W., N. A. Crook, C. K. Mueller, J. Sun, and M. Dixon, 1999: Nowcasting thunderstorms: a status report. Bull. Amer. Meteor. Soc., 79, 2079-2099.

Yamada, H., B. Geng, K. K. Reddy, H. Uyeda, and Y. Fujiyoshi, 2003: Three-dimensional structure of a mesoscale convective system in a Baiu-frontal depression generated in the downstream region of the Yangtze river. J. Meteor. Soc. Japan, 81, 1243-1271.

Zhang, C. Z., H. Uyeda, H. Yamada, B. Geng, and Y. Ni, 2006: Characteristics of mesoscale convective systems over the east part of continental China during Meiyu from 2001 to 2003. J. Meteor. Soc. Japan, 84, 763-782. 